\title{
Reemergence of Antarctic sea ice predictability and its link to deep ocean mixing in global climate models
}

\author{
Sylvain Marchi · Thierry Fichefet · Hugues \\ Goosse • Violette Zunz • Steffen Tietsche • \\ Jonathan J. Day • Ed Hawkins
}

7 Received: date / Accepted: date

8 Abstract Satellite observations show a small overall increase in Antarctic sea ice 9 extent (SIE) over the period 1979-2015. However, this upward trend needs to be 10 balanced against recent pronounced SIE fluctuations occurring there. In the space of 1 three years, the SIE sank from its highest value ever reached in September 2014 to 2 record low in February 2017. In this work, a set of six state-of-the-art global climate 3 models is used to evaluate the potential predictability of the Antarctic sea ice at such 4 timescales. This first multi-model study of Antarctic sea ice predictability reveals that the ice edge location can potentially be predicted up to three years in advance. However, the ice edge location predictability shows contrasted seasonal performances, with high predictability in winter and no predictability in summer. The reemergence of the predictability from one winter to next is provided by the ocean through its large thermal inertia. Sea surface heat anomalies are stored at depth at the end of the winter and influences the sea ice advance the following year as they resurface. The effectiveness of this mechanism across models is found to depend upon the depth of the mixed layer. One should be very cautious about these potential predictability estimates as there is evidence that the Antarctic sea ice predictability is promoted by deep Southern Ocean convection. We therefore suspect models with excessive convection to show higher sea ice potential predictability results due to an incorrect representation of the Southern Ocean.

Keywords Predictability · Sea ice · Southern Ocean · Model intercomparison ·

Deep convection

S. Marchi · T. Fichefet · H. Goosse

Georges Lemaître Centre for Earth and Climate Research, Earth and Life Institute, Université catholique de Louvain, Louvain-la-Neuve, Belgium

Tel.: +32 10473067

E-mail: sylvain.marchi@uclouvain.be

V. Zunz

Department of Geography, Vrije Universiteit Brussel, Brussel, Belgium

S. Tietsche · J.J. Day

European Centre for Medium-Range Weather Forecasts, Reading, UK

E. Hawkins

NCAS-Climate, Department of Meteorology, University of Reading, Reading, UK 


\section{Introduction}

Unlike the rapid sea ice losses reported in the Arctic, the Antarctic SIE has been increasing during the 1979 to 2015 period for all seasons (Comiso et al (2017)), despite global warming. This small overall increase is a balance between large regional variations. The Ross Sea and the eastern Antarctic sector positively contribute to the sea ice cover increase, while the Amundsen and Bellingshausen Seas negatively contribute to it (e.g., Parkinson and Cavalieri (2012); Comiso et al (2017)). This sea ice expansion is seemingly at odds with the evolution of sea ice simulated by almost all today's climate models, which show a significant decrease in sea ice cover over the same period (Turner et al (2013a)). The inconsistency between the observed and simulated sea ice may reflect a deficient or even missing representation of the physical processes governing the Antarctic sea ice. Interestingly, Meehl et al (2016) found that the models which correctly sample the observed natural variability of the SIE over 2000-2014 within the fifth phase of the Coupled Model Intercomparison Project (CMIP5) also capture the expansion of the SIE in all seasons.

The evolution of the Antarctic sea ice at the seasonal-to-interannual timescales has been related to both atmospheric and oceanic processes. The two studies of Gordon and Taylor (1975) and Martinson (1990) notably initiated the understanding of the interactions between the sea ice, the winds and the ocean. Over the last decades, multiple mechanisms have been proposed as potential drivers of the Antarctic sea ice cover changes. As yet, none of them has provided a single and fully satisfactory explanation. Several studies traced recent changes in atmospheric circulation patterns in the Antarctic, and possible impact on Antarctic sea ice, to teleconnections with the tropical Pacific and Atlantic Oceans (Ding et al (2011); Okumura et al (2012); Li et al (2014); Simpkins et al (2014); Meehl et al (2016)). A positive Southern Annular Mode (SAM) - associated with an intensification and a poleward shift of the westerly winds - is also expected to promote an overall sea ice expansion due to an increased equatorward Ekman transport of cold surface waters (Thompson et al (2011)), with a noticeable exception in the West Antarctic region. In this region, the Amundsen Sea Low (ASL) variability influences the climate by controlling the meridional component of the large-scale atmospheric circulation. This results in a reduced SIE in the Bellingshausen and eastern Amundsen Seas and an increase in the western Amundsen and Ross Seas (e.g., Stammerjohn et al (2008); Turner et al (2013b); Raphael et al (2016)). Nevertheless, climate general circulation models (GCMs) fail at reproducing the observational link between SAM, SST and Antarctic sea ice on the inteannual timescale. They even tend to produce an ocean surface warming and a sea ice lost in response to a strengthening of the SAM (e.g., Bitz and Polvani (2012); Sigmond and Fyfe (2014); Haumann et al (2014)). Ferreira et al (2015) sheds light on this apparent disagreement by introducing a two timescale response. While the strengthening of the westerly winds leads to an initial surface cooling and sea ice expansion, the long-term response is that of a surface warming and sea ice loss. Purich et al (2016) recently argued that part of this disagreement lies in the model underestimation of westerly wind changes. To explain the sea ice expansion during the last decades, it has also been suggested that freshwater influx from basal melt of ice shelves could favour the formation of sea ice locally through an enhanced stratification (Bintanja et al (2013)). This is though a contentious issue since both Swart and Fyfe (2013) and Pauling et al (2016) were unable to confirm this mechanism. At the regional scale, Holland and Kwok (2012) identified wind-driven dynamic and thermodynamic 
changes as the principal cause of the observed sea ice cover trends. However, it is unclear how the wind-driven sea ice transport alone could explain the observed concurrent sea surface temperatures (SST) downward trends. This problem is partly figured out over the seasonally sea ice covered region with the ice-ocean feedback introduced by Goosse and Zunz (2014) and observationally proven and quantified by Lecomte et al (2017).

The year 2016 has been marked by anomalous atmospheric circulation patterns, mainly in the Weddell Sea and Ross Sea sectors, which prevailed throughout the springtime and lead to strong winds and advection of warm air from the north. Those atmospheric conditions, associated with a strong negative November SAM index, induced a massive sea ice melt (Turner et al (2017)), causing the Antarctic sea ice in 2017 to shrink to its smallest summer extent on record since the beginning of satellite observations. Stuecker et al (2017) also attributed this unprecedented low Antarctic SIE to positive SST anomalies, caused by an extreme El Niño event that peaked in over the period December 2015-February 2016 and a concurrent negative phase of the SAM. The 2017 record low came a bit more than two years after several monthly record high SIEs in 2014 and decades of moderate sea ice growth. Those rapid changes highlight the importance of SIE natural variability in the Antarctic. According to Armour et al (2011), however, this increasing variance should not be interpreted as a warning sign of an approaching tipping point for the Antarctic sea ice.

Most CMIP5 models notably fail in reproducing the natural variability of the Antarctic sea ice (e.g., Turner et al (2013a); Zunz et al (2013)). Those two studies pointed out marked seasonal variations of the interannual variability simulated for each month of the year compared to the observations, as well as an overestimation of the observed winter interannual variability. In addition, much of the SIE variability in models originates from changes in intensity of deep ocean convection (e.g., Latif et al (2013); Behrens et al (2016)). As yet, there was no clear evidence of this relation in recent observations. However, the return of the Weddell polynya in winter $2017 \mathrm{might}$ support the existence of a multi-decadal internal mode of variability in the Southern Ocean, suggesting that natural variability alone could have explained the Antarctic sea ice expansion over the last decades (Polvani and Smith (2013); Mahlstein et al (2013); Zunz et al (2013)).

Until now, Antarctic sea ice predictability has not received much attention. Due to the lack of observations and model biases, the scientific community has mainly focused on idealised studies so far. Holland et al (2013) characterised the initial value predictability of the ice edge location in the coupled atmosphere-ocean-landsea ice model CCSM3. They found that the predictability up to two years ahead is mainly driven by oceanic processes through the reemergence of previous winter SST conditions. Those processes are responsible for intermittent performance with low summer and high winter predictability, this behaviour being closely related to the seasonal magnitude of the vertical ocean mixing. Zunz et al (2014) applied different initialisation procedures to the Earth system model of intermediate complexity, LOVECLIM1.2, and evaluated their impact on sea ice predictability in the Southern Ocean. They confirmed the role of the ocean as a source of sea ice predictability at the interannual timescale (two years ahead). They also addressed the sea ice predictability at the multi-decadal (10-30 years) timescale. They found a significant correlation of the SIE trend between the hindcasts and the pseudo-observations over the period 10-30 years. Finding that, initialisation systematically improved those 
correlations. However, much work still has to be done to harness this potential predictability in a real prediction system. Using CMIP5 decadal hindcasts, Yang et al (2016) showed poor Antarctic sea ice predictive skill on all timescales irrespective of whether the projections were initialised or not. This is an indication that more effort should be invested in order to understand the origin of the deficiencies in real forecast performance. Should those deficiencies primarily originate from a sparse and incomplete knowledge of Antarctic initial conditions and or model biases, or should they rather be attributed to limited model predictive skill at the seasonal-tointerannual timescales? This question motivated our model intercomparison study. We assessed in a systematic way the Antarctic sea ice predictive skill of multiple climate models and showed that the predictive skill is highly model-dependent. This model intercomparison allowed us to identify robust Antarctic sea ice predictability characteristics and possible related mechanisms inherent to up-to-date GCMs, creating the potential for skilful Antarctic sea ice forecasts at the seasonal-to-interannual timescales.

Our work follows on from numerous studies dedicated to the predictability of Arctic sea ice, carried out within the Arctic Predictability and Prediction on Seasonal to Inter-annual Timescales (APPOSITE) project (Day et al (2016))). This project aimed to define the scope of useful climate predictions in the Arctic, including the identification of the timescales on which Arctic climate is potentially predictable. The ability to perform accurate predictions of the Arctic climate was tackled with several GCMs. Additional information about this project is available at http://arp.arctic.ac. $\mathrm{uk} /$ projects/arctic-predictability-and-prediction-seasonal-inte/. Although this dataset was initially designed to address Arctic climate predictability, we benefited from global climate simulations to explore the predictability of the Antarctic sea ice. This study should be regarded as an extension for the Antarctic of that conducted by Tietsche et al (2014) in this respect.

We proceed in Section 2 with a brief introduction to the idealised experiments that we used. A detailed description of the APPOSITE simulations can be found in Day et al (2016). We then give a general overview of the mean climate state (SIE and mixed layer depth (MLD)) simulated by the six models utilised. We conclude Section 2 with a description of the metric used to assess the predictability of the sea ice edge location. The results of the predictability of the ice edge location are then presented in Section 3 and discussed in Section 4 in light of the results that we gained from the analysis of the predictability of the ocean heat content computed over its first 100 metres.

\section{Methodology}

\subsection{The APPOSITE project}

This study aims at giving an overview of the ability of today's GCMs to predict the Antarctic sea ice on seasonal-to-interannual timescales. Due to its nonlinear nature, the climate system is highly sensitive to small perturbations in the initial state at such timescales. As both observations and models are incomplete and error-prone, it is difficult to correctly estimate the part of the total uncertainty accounted for the initial state. In order to statistically address the sensitivity to the initial conditions, the models were run from a set of initial conditions. 
Six coupled atmosphere-ocean-sea ice GCMs were used to assess the initial-value predictability of Antarctic sea ice. They all include a fully prognostic sea ice component (see Table 1). After a spin-up phase of at least 100 years that ensure the models to be close to equilibrium, long control simulations with constant radiative forcing representative of the end the 20th century (see Table 1) were conducted in order to have a good estimate of the mean state and internal variability of the system (further discussed in Section 2.2). These simulations were used as a reference to evaluate the predictability arising from the knowledge of the initial conditions (see Section 2.3). It appeared as though that the models do not settle down into a stable climate after the spin-up phase, leading to a drift in the simulated SIE (see Section 2.2). This situation was already reported in Day et al (2016) in the Arctic for many models and turns out to be true for all the models in the Antarctic. The influence of this drift on the metric used to assess the predictability is discussed in Section 2.3.

The ensemble experiments were generated from the control simulations on multiple start dates. Within a given ensemble, each ensemble member was initialised from the same atmosphere, land and sea ice conditions. They only differ by a slightly modified ocean state, a white noise of amplitude $10^{-4} \mathrm{~K}$ being applied to the SSTs. This perturbation is tiny enough to assume a virtually perfect knowledge of the initial state. The number of start dates varies between 8 and 18. They are sufficiently spaced in time to encompass a wide range of sea ice conditions (see Figure S1 of the supplementary material). Each ensemble includes from 7 to 16 members depending on the model. The number of ensembles and ensemble members for each model is specified in Table 1. The APPOSITE project was originally designed to assess late summer sea ice conditions in the Arctic. That is why the models all provided with ensemble experiments initialised on July 1st even if this requirement is not relevant for Antarctic sea ice predictability. Some models also contributed to the predictability experiments with simulations initialised on January 1st, May 1st and November 1st (see Table 1). Irrespective of the start month, all the predictions are 36 months long except for MIROC5.2, which are 42 months long.

\subsection{Models' mean state and internal variability}

\subsubsection{Sea ice}

Figure 1 illustrates how the Antarctic SIE is simulated by the six models. Though the annual cycle of the SIE is correctly reproduced with a maximum SIE in September and a minimum SIE in February, the simulated SIE does not track the observations. It bears emphasizing that most today's GCMs fail to reproduce the correct magnitude of the SIE all over the year (refer to Turner et al (2013a) and Zunz et al (2013) for a discussion of the CMIP5 models mean state). Most of the models selected here (EC-Earth2.2, ECHAM6-FESOM, GFDL CM3, MIROC5.2 and MPI-ESM-LR) tend to underestimate the SIE. The situation is particularly problematic for ECHAM6FESOM and MIROC5.2, those models producing little sea ice in winter with no remaining sea ice in summer. HadGEM1.2 is the only one to produce too much sea ice throughout the year. It is worth noticing that a model that simulates a small SIE in winter consistently produces a small SIE in summer and vice versa. Looking at the sea ice concentration (SIC) field patterns in Figure S2 of the supplementary 


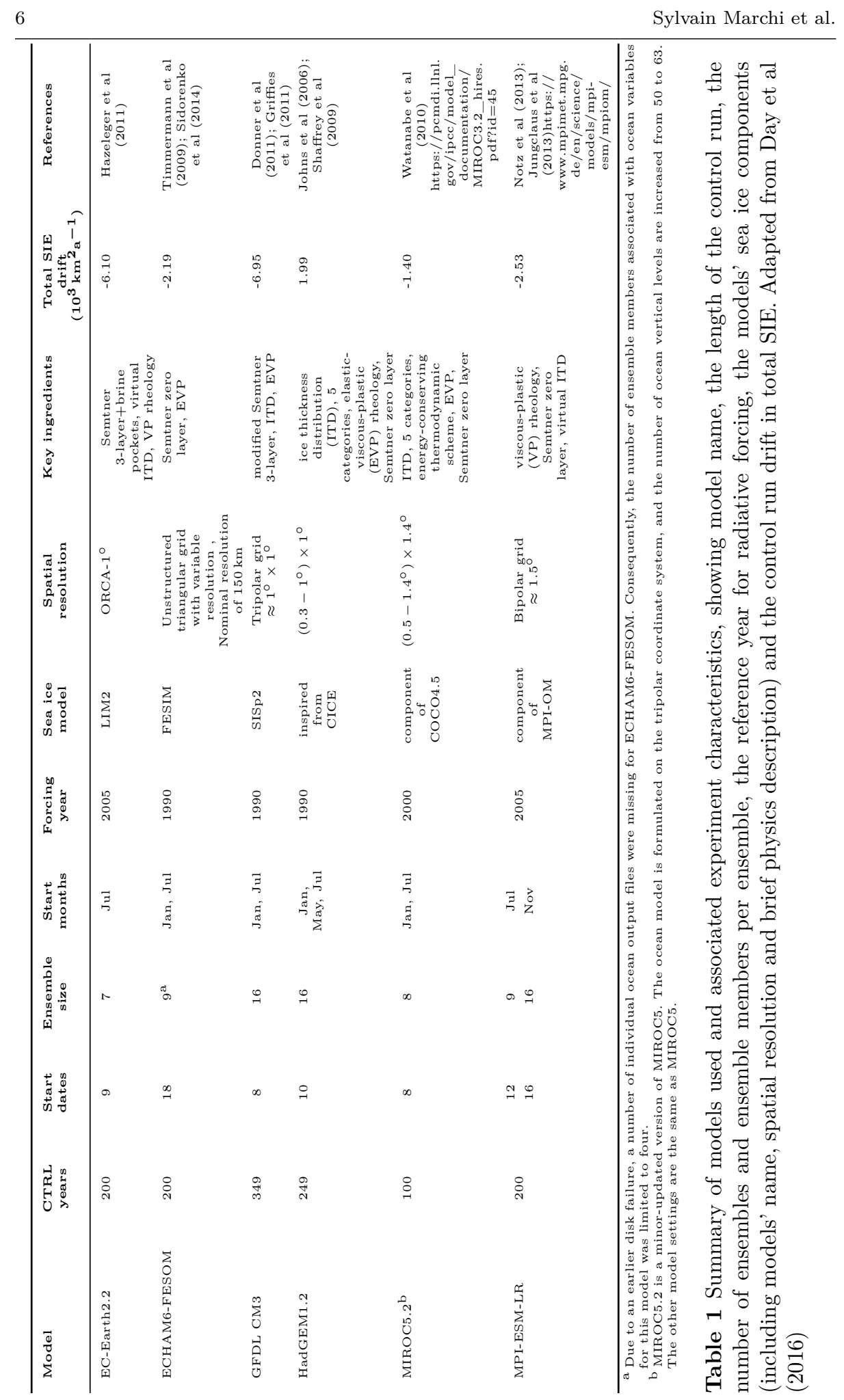


material reveals that the Weddell Sea contributes much of the remaining summer sea ice.

Like the SIE mean state, the internal variability of the SIE simulated by the models is in disagreement with observations. The standard deviation of the observed SIE is nearly flat throughout the year, whereas it shows marked seasonal variations in the models. This is especially true for ECHAM6-FESOM, MIROC5.2 and MPIESM-LR. All the models but HadGEM1.2 tend to have their minimum of variability in February. This minimum of variability coincides with the minimum of SIE and probably results from it. At the regional scale (see Figure S3 of the supplementary material), the observed internal variability of the SIE is ring-shaped in winter. The interior of the sea ice is in fact characterised by smooth variations of the SIC field and most of the variability is limited to the marginal ice zone. This is in sharp contrast with the variability simulated by the models. Although they succeed in reproducing the high SIC variability in the marginal sea ice zone, most of them tend to produce too much SIC variability within the pack. The SIC variability patterns shown in Figure S3 of the supplementary material are representative of the magnitude of the interannual variations of the ice edge position. Much of the SIC variability within the pack must therefore not be ascribed to the sea ice drift observed in the control simulations. We will see in Section 2.2.2 that those extensive areas of large SIC variability are characterised by anomalous open-ocean deep convection events (see figure 3$)$.

We mentioned in Section 2.1 that the APPOSITE control runs are subject to a drift, i.e. a long-term trend. This is especially clear for the SIE. The magnitude of the annual drift is given in Table 1, while the plots of the September control run SIE and associated drift are provided in Figure S1 of the supplementary material. Those diagnostics show that all the models have a negative September SIE trend, except HadGEM1-2 which has a positive one. All trends are significant at the 95 percent level.

From this perspective, GCMs leave room for improvement concerning the Antarctic sea ice. Nevertheless, this glaring disagreement between models and observations fully justifies the use of a perfect model approach as it helps to gain insight into the predictability properties of the Antarctic sea ice.

\subsubsection{Mixed layer}

The mixed layer south of the Antarctic circumpolar current (ACC) is strongly influenced by the presence of sea ice (Martinson (1990); Pellichero et al (2017)). Marked seasonal variations of the mixed layer depth are observed in this part of the Southern Ocean with values exceeding $100 \mathrm{~m}$ at some locations (Pellichero et al (2017)). The seasonal cycle of the MLD closely follows the seasonal cycle of the sea ice (not shown). Winter cooling and formation of sea ice destabilize the water column and deepen the mixed layer, while warming and freshening of the surface, associated with the summer sea ice melting, cause the mixed layer to shallow. This observational link between the sea ice and the mixed layer has also been reported in models (see for instance Barthélemy et al (2015)).

The depth of the mixed layer is important as it reflects the amount of water and accumulated heat which is directly available to interact with sea ice. As a consequence, it is essential to correctly represent the mixed layer in the regions covered by sea ice in climate models to properly simulate the observed mean state of the sea 


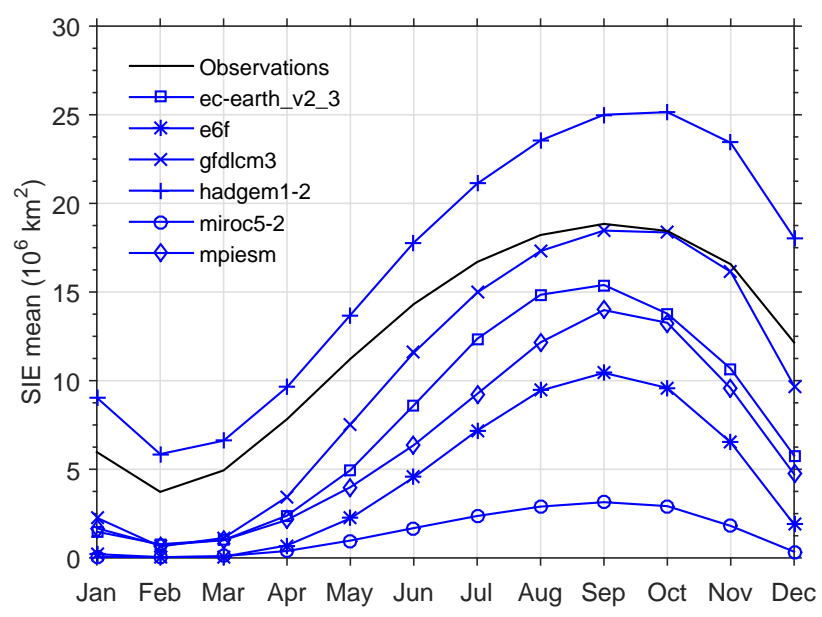

(a) SIE mean state

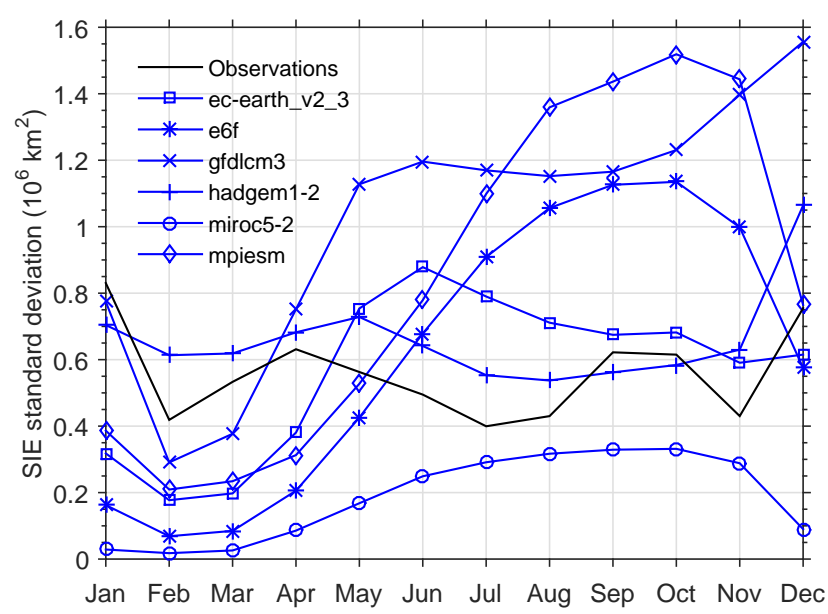

(b) SIE variability

Fig. 1 Characteristics of the Antarctic SIE simulated by the six models (up: the mean over the control run years for each individual month; down: the standard deviation over the same period and for each month too. The SIE was previously detrended before computing the standard deviation). The mean observed SIE and the associated standard deviation are also shown for comparison. They were retrieved from the global sea ice concentration data record (SSMI/SSMIS) of the Ocean and Sea Ice Satellite Application Facility (OSI SAF, EUMETSAT (2015)). This dataset covers the period October 1978 to April 2015 and has a spatial sampling of $10 \mathrm{~km}$ and $12.5 \mathrm{~km}$. The performance of this dataset is discussed in Ivanova et al (2015) 
ice and its natural variability. Besides, we will show in Sections 4.1 and 4.2 that the penetration of the SST anomalies in the ocean is closely tied to the seasonal cycle of the MLD in the regions seasonally capped by sea ice. Temperature fluctuations at the base of the mixed layer reflect the temperature fluctuations at the surface. For sufficiently deep winter mixed layers, the winter temperature anomalies at depth are likely to persist and influence the surface temperatures the following year. We thus found useful to discuss the ability of our six models to represent the seasonal evolution of the MLD.

The lack of in-situ measurements makes difficult to explore the mixed layer characteristics in the Southern Ocean, especially in the zone seasonally covered by sea ice. Recently, Pellichero et al (2017) constructed a 10-year climatology of the MLD in this ocean by examining more than 465,000 hydrographic profiles. Those profiles combine several sources of information, including elephant seal-derived observations, ship-based and Argo float observations. The MLD was retrieved from density profiles by combining three criteria that give three estimates of the MLD, following the approach of Holte and Talley (2009). One of the criteria consists in inspecting the shape of each individual profile, while the two others are based on a density threshold of $0.03 \mathrm{kgm}^{-3}$ and vertical density gradient of $0.0005 \mathrm{kgm}^{-3} \mathrm{dbar}^{-1}$. Figure 2 shows the mean state of the observed MLD averaged over the summer months (January, February and March), the winter months (July, August and September) as well as the amplitude of the seasonal cycle (defined as the difference between the mean winter MLD and the mean summer MLD). Those three quantities were also computed for the six models.

Although the models that we used provided an MLD diagnostic, we decided not to work with it for two reasons. Firstly, we noticed that the definition of the MLD is not always clearly stated in the model description so that different models might use different criteria. Secondly, the models for which the method of calculation is not reported probably follow the density $\sigma_{\theta}$ threshold of $0.125 \mathrm{kgm}^{-3}$ from the near surface recommended by CMIP5. Heuzé et al (2013) showed that this value is too high to detect the real MLD in the weakly stratified Southern Ocean. Consequently, the most appropriate criterion $\Delta \sigma_{\theta} \geq 0.03 \mathrm{kgm}^{-3}$ was selected in this study (the reader is referred to Sallée et al (2006) and de Boyer Montégut (2004) for more details). This choice of density threshold value criterion was also motivated by the comparison to the observations, as this criterion was used to produce the mixed layer climatology discussed above. Note that the potential density was directly available for the three models GFDL CM3, MPI-ESM-LR and MIROC5.2, while it needed to be computed from monthly mean potential temperatures and salinities for ECEarth2.2, ECHAM6-FESOM and HadGEM1.2.

It can be seen from Figure 2 (left column) that the MLD simulated by the models in summer is spatially uniform over the part of the Southern Ocean seasonally capped by sea ice. Besides, it rarely exceeds $50 \mathrm{~m}$. This value is close to the observed summer MLD. Much of the differences between the simulated and observed MLDs arise in winter. The winter MLDs simulated by ECHAM6-FESOM, GFDL CM3, HadGEM1.2, MIROC5.2 and MPI-ESM-LR are consistently larger than the observations almost everywhere in the Southern Ocean. Apart from the coast, the EC-Earth2.2 model is the only model which simulates too shallow mixed layers over the regions seasonally covered by sea ice. Despite the reported magnitude biases, the broad meridional evolution of the winter MLD simulated by the six models fits with the climatology of Pellichero et al (2017). All the models simulate deep mixed layers 


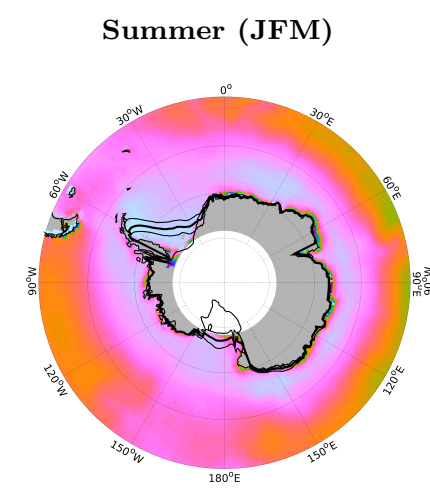

Winter (JAS)

Seasonal cycle amplitude
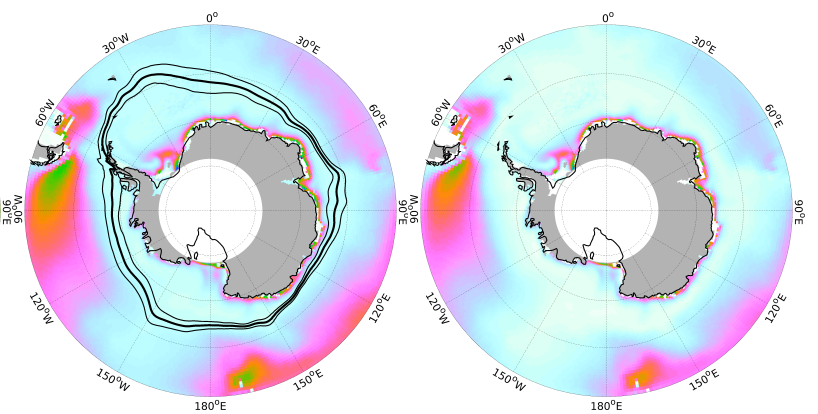

(a) EC-Earth2.2
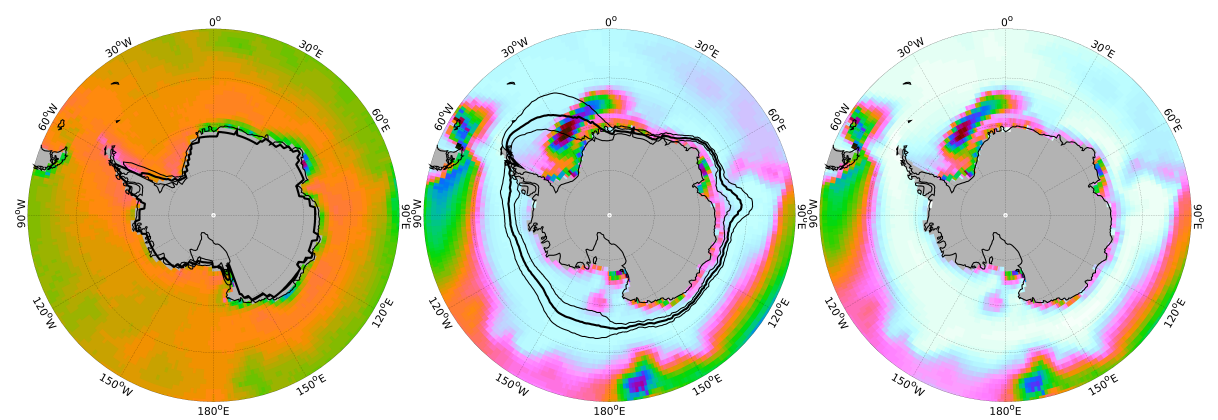

(b) ECHAM6-FESOM
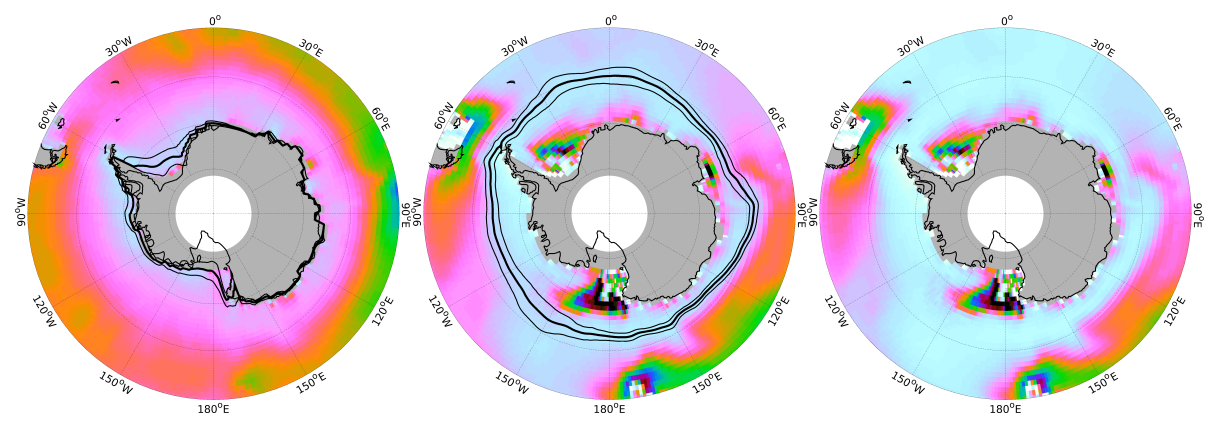

(c) GFDL CM3
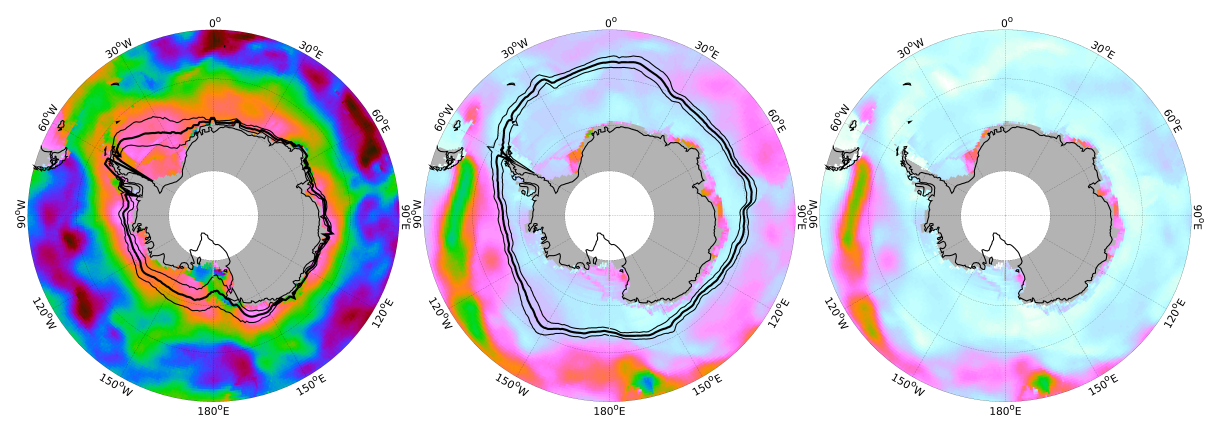

(d) Climatology

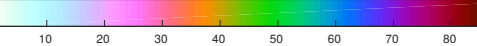

Fig. 2 Representation of the summer MLD (left), winter MLD (centre) and amplitude of the MLD seasonal cycle (right) averaged over the control run years for EC-Earth2.2, ECHAM6-FESOM and GFDL CM3. MLDs values are in metres. The colour scale is limited to values between 0 and $100 \mathrm{~m}$ for the summer, while it is extended to $700 \mathrm{~m}$ for the winter and the amplitude of the seasonal cycle. The winter MLD simulated by GFDL CM3 can exceed this threshold value, but only for a restricted number of grid points. The maximum winter MLD is $1262 \mathrm{~m}$ and $895 \mathrm{~m}$ for GFDL CM3 in the Indian Ocean and the Ross Sea, respectively. The mean state (standard deviation) of the ice edge location in summer and winter is represented by the thick (thin) black curve(s). Note that, for the models, the standard deviation of the ice edge location was computed from the detrended ice edge location time series for each month and each longitude separately. The MLD climatology of Pellichero et al (2017) is also presented with the observed ice edge location and its standard deviation, for comparison. The ice edge location was retrieved from the global sea ice concentration data record (SSMI/SSMIS), which covers the period October 1978 to April 2015 (OSI SAF, EUMETSAT (2015)) 


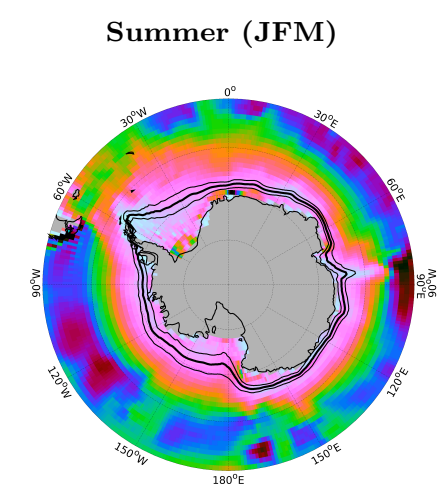

Winter (JAS)

Seasonal cycle amplitude

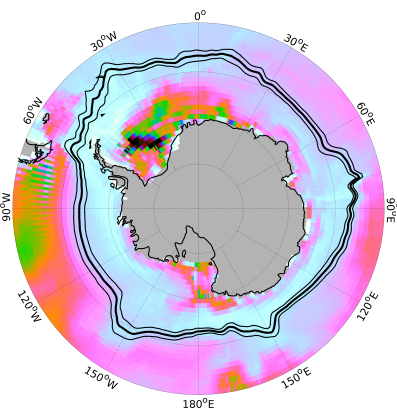

(e) HadGEM1.2
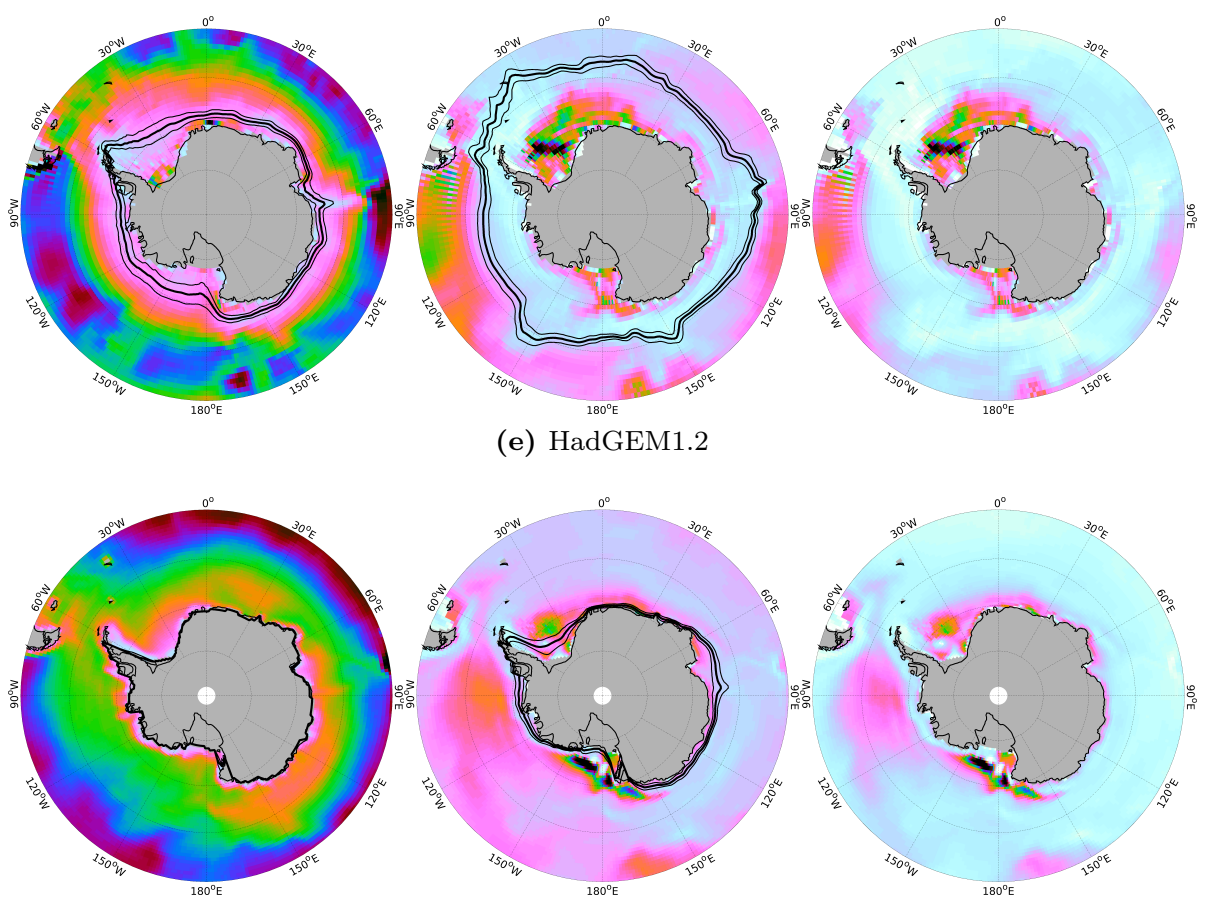

(f) MIROC5.2
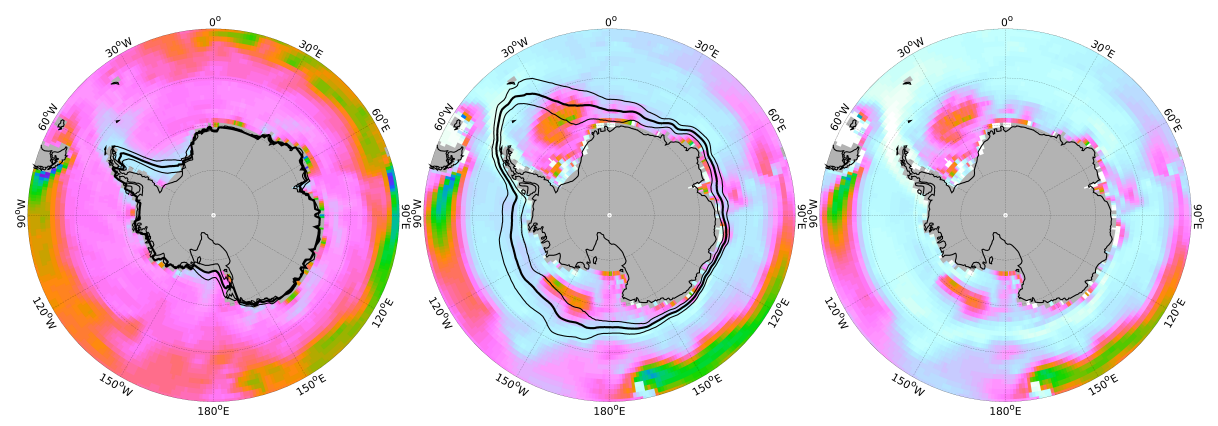

(g) MPI-ESM-LR
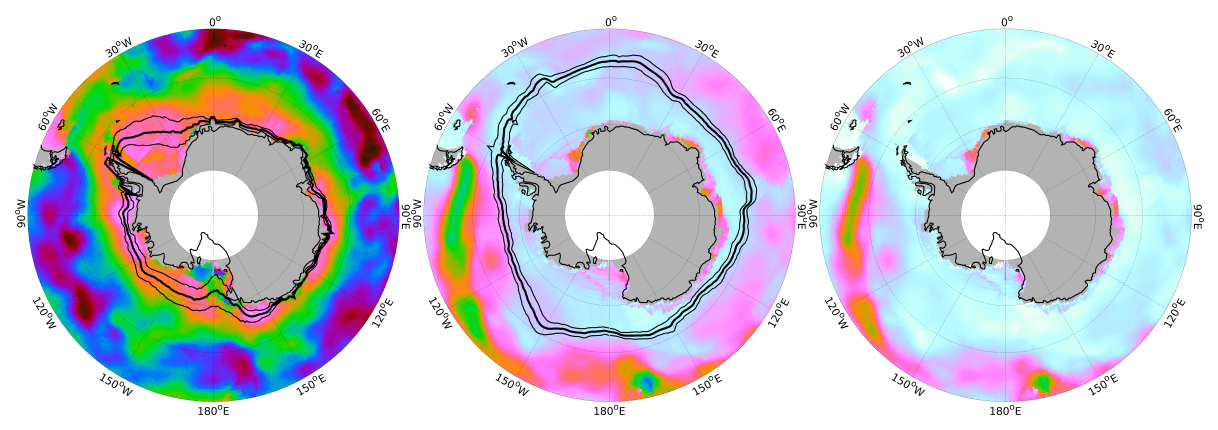

(h) Climatology

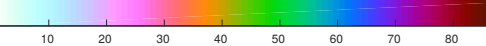

Fig. 2 (cont.) Same as before, but for HadGEM1.2, MIROC5.2 and MPI-ESM-LR. MLDs values are still in metres. The winter MLD simulated by HadGEM1.2 and MIROC5.2 go up to $1169 \mathrm{~m}$ and $1337 \mathrm{~m}$ at some grid points, respectively. The MLD climatology of Pellichero et al (2017) is presented with the observed ice edge location and its standard deviation, for comparison. The ice edge location was retrieved from the global sea ice concentration data record (SSMI/SSMIS), which covers the period October 1978 to April 2015 (OSI SAF, EUMETSAT (2015)) 
in coastal areas and in the vicinity of the ice shelves. They typically reach the ocean floor, which is in agreement with observations. Those coastal areas are associated with the production of dense waters. Unlike observations, the deep coastal mixed layers also extend to the open ocean in ECHAM6-FESOM, GFDL CM3, HadGEM1.2, MIROC5.2 and MPI-ESM-LR. Such open ocean deep mixed layers are almost exclusively found in the Ross and Weddell Seas. The mean state of the winter MLD at those locations can go up to $700 \mathrm{~m}$ depending on the model. It even locally exceeds $1000 \mathrm{~m}$ in GFDL CM3, HadGEM1.2 and MIROC5.2. Away from the deep open ocean mixed layers, the MLD never exceeds $120 \mathrm{~m}$. This zone of intermediate MLD values encloses the continent and extends over the ACC front, where the mixed layer deepens again.

Heuzé et al (2013) reported those open ocean regions as the source of much Antarctic dense bottom water formation in CMIP5 models, while the production of dense bottom water at those locations is extremely rare in observations. Figure 3 shows the maximum MLD found in the control run for each individual grid point. The blue contour in each individual map encloses the regions where the maximum MLD exceeds half of the whole water column. The identified areas correspond to the regions where deep convection is likely to occur. Heuzé et al (2013) asserted that the regions defined in this way are insensitive to the criterion used to detect deep convection. Figure 3 indicates that deep convection events are widespread and occur in the vicinity of the coast as well as in the open ocean, where the deepest MLDs are found. In contrast to the five other models, EC-Earth2.2 simulates few deep convection events in the open ocean. The infrequency of those events in the Weddell Sea accounts for the shallow mean state of the winter MLD in Figure 2.

\subsection{Metric used to assess the predictability}

In order to assess the initial-value predictability, we characterised the ensemble predictions with the prognostic potential predictability (PPP) introduced by Pohlmann et al (2004). This metric has been extensively used in idealised potential predictability studies (see for instance Koenigk and Mikolajewicz (2008); Holland et al (2013); Zunz et al (2014); Hawkins et al (2016)).

The PPP basically compares the variance of the ensemble predictions (which gives an idea of the ensemble spread) to the variance of some reference forecast, chosen in this case as the control simulation variance $\sigma_{\text {clim }}^{2}$ :

$$
\operatorname{PPP}(t)=1-\frac{\frac{1}{(N(M-1))} \sum_{i=1}^{N} \sum_{j=1}^{M}\left(x_{i j}(t)-\bar{x}_{i}(t)\right)^{2}}{\sigma_{\text {clim }}^{2}}
$$

where $x_{i j}(t)$ is the simulated value of some climate variable $x$ at time $t$ for the $j$ th member of the $i$ th prediction ensemble, and $\bar{x}_{i}(t)$ denotes the ensemble mean at time $t$ for the ensemble $i$. $i$ ranges from 1 to $N$, the number of ensembles, while $j$ ranges from 1 to $M$, the number of members per ensemble. A PPP value of 1 indicates perfect predictability (all members forecast the same evolution of the variable $x$ ). Conversely, a value of 0 means that the ensemble variance converges to the variance of the reference simulation. This last situation implies that no more information can be extracted from the knowledge of the initial state. As in Pohlmann et al (2004), 


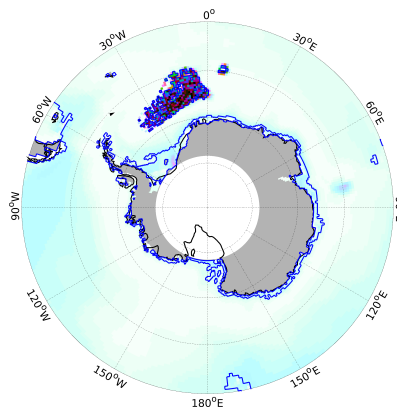

(a) EC-Earth2.2

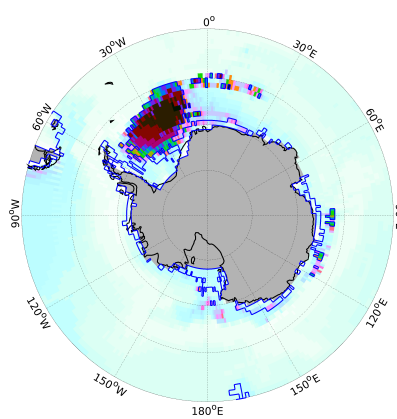

(d) HadGEM1.2

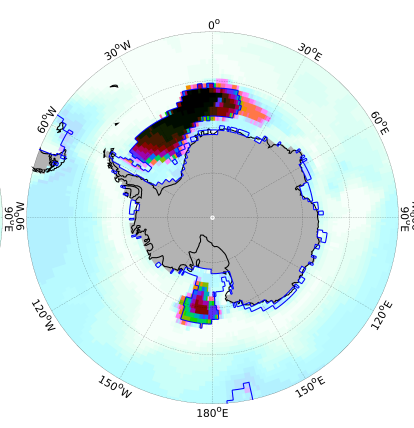

(b) ECHAM6-FESOM

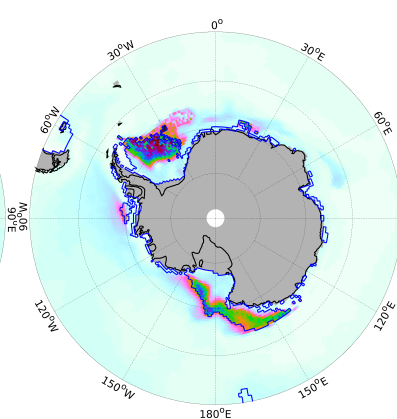

(e) MIROC5.2

(g) Climatology

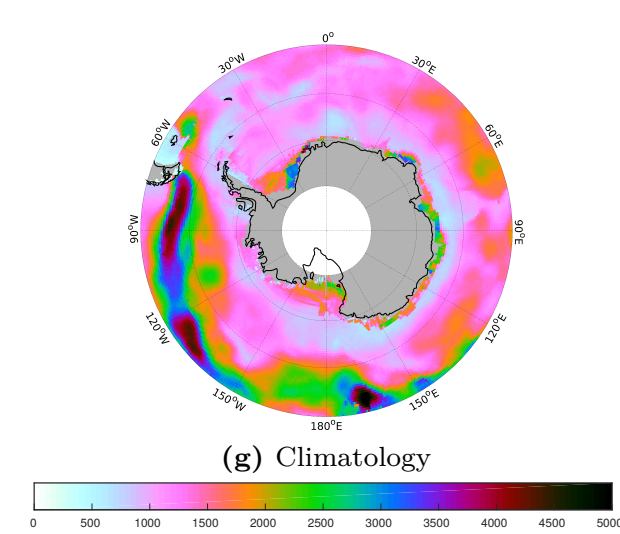

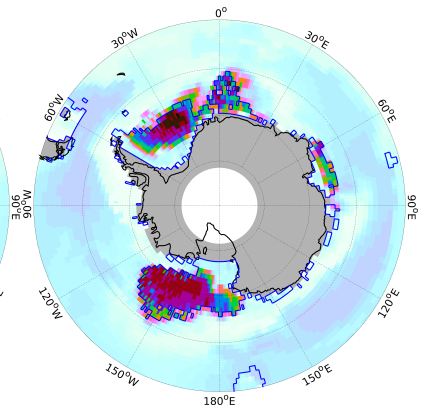

(c) GFDL CM3

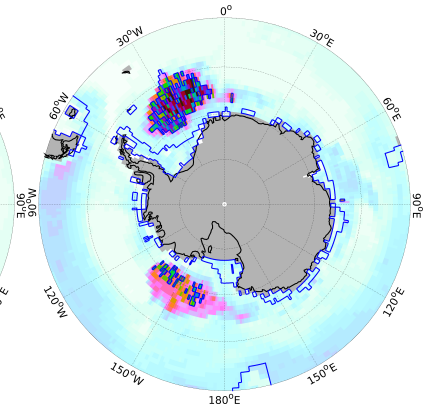

(f) MPI-ESM-LR

Fig. 3 Maximum MLD (in metres) found in the control run for each model. The colour scale is limited to values between 0 and $5000 \mathrm{~m}$. The blue line encloses the regions of the Southern Ocean where the MLD over bathymetry quotient exceeds $50 \%$. The maximum MLD climatology of Pellichero et al (2017) is also shown for comparison, with colour scale values ranging from 0 to $500 \mathrm{~m}$ 
the statistical significance of the PPP was estimated using an F-test which takes into account the effect of serial correlation in the control run time series.

Metrics like the PPP are known to be sensitive to the method used for choosing the reference climatology (see Hawkins et al (2016)). In the special case of the PPP, this choice has a direct impact on $\sigma_{\text {clim }}$, the standard deviation of the reference climatology. A drift in the control simulations leads to higher values of $\sigma_{\text {clim }}^{2}$ than would be expected in a steady state. As a result, $\sigma_{\text {clim }}^{2}$ may be higher than the limit of ensemble variance and leads to overoptimistic PPP estimates. Similarly, it is also important to compute the variance of the control time series for each of the 12 calendar months, rather than having a single estimate, to include the potential influence of marked seasonal variations of the variance (as depicted in Figure 1b for the SIE standard deviation). Thus we systematically removed, for all variables, the linear trend of the control time series for each month of the year, before calculating the variability of the control simulation. The post-processed variables like the ice edge location and the ocean heat content were first computed from the undetrended sea ice concentration and temperature fields and, then, we detrended the corresponding time series. We expect the PPP values presented to give an unbiased estimate of the predictability for each model. However, this transient climate may affect the properties of the climate system, thus influencing its predictability. Nonetheless, more start dates would be required to correctly sample the predictability of the system over the same baseline climate and thus robustly investigate the state dependency of the predictability.

\section{Results}

\subsection{Predictability of the ice edge location}

We applied the PPP metric to the ice edge location as in Holland et al (2013). It is defined for each longitude as the northernmost latitude where the Southern Hemisphere SIC exceeds $15 \%$. Each panel of Figure 4 shows the PPP computed for a given model. The time evolution of the PPP throughout the 36 months of integration (42 for MIROC5.2) is plotted along the horizontal axis, i.e. from left to right, all the ensemble experiments starting on July 1st. The six models display high values, i.e. close to one, during the first months of integration, even though we already notice some meridional differences. Predictability of the ice edge location rapidly falls to nearly zero in EC-Earth2.2 everywhere, whereas PPP remains high in the other models until December at some locations. The summer (January, February and March) is then characterised by low and generally not significant PPP values in many locations. This feature is shared by all the models. This period when the ice edge is not predictable is followed by a marked increase of the PPP at the beginning of the sea ice growing season around May. All models apart from EC-Earth2.2 share this feature.

The reemergence of the predictability of the ice edge location is consistent with previous studies (Holland et al (2013); Zunz et al (2014)), despite the choice of a different start month (January 1st). This suggests that skilful interannual sea ice predictions could be achieved from various start months, not just January. This is confirmed by looking further at the role of the start month for each model separately, by applying the PPP metric to the other start months available. Figures are provided 


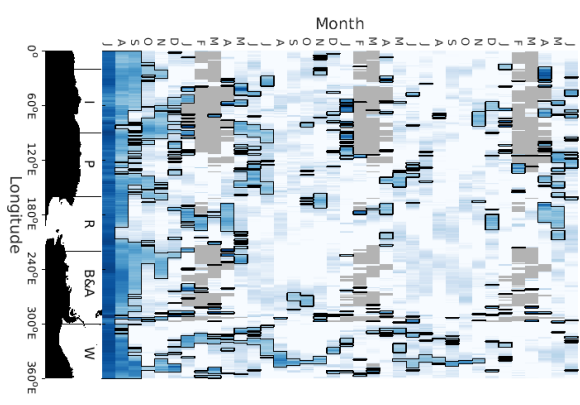

(a) EC-Earth2.2

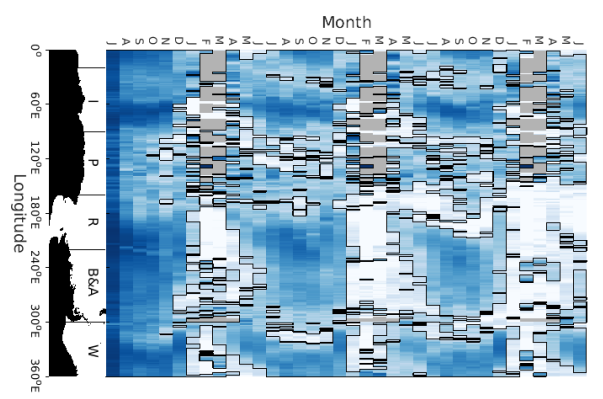

(c) GFDL CM3

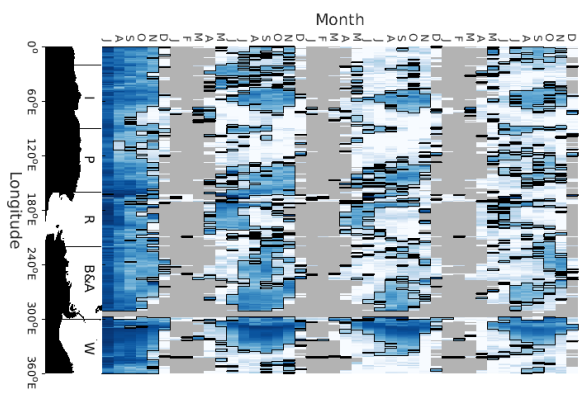

(e) MIROC5.2

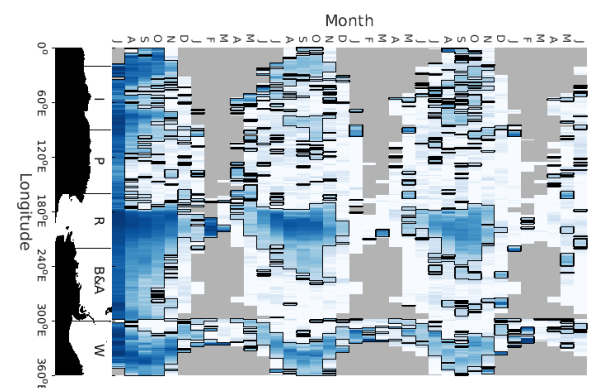

(b) ECHAM6-FESOM

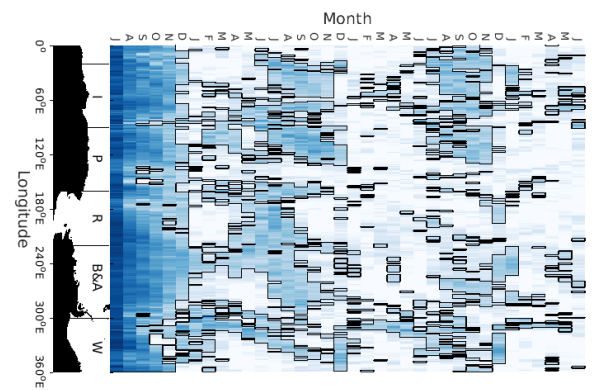

(d) HadGEM1.2

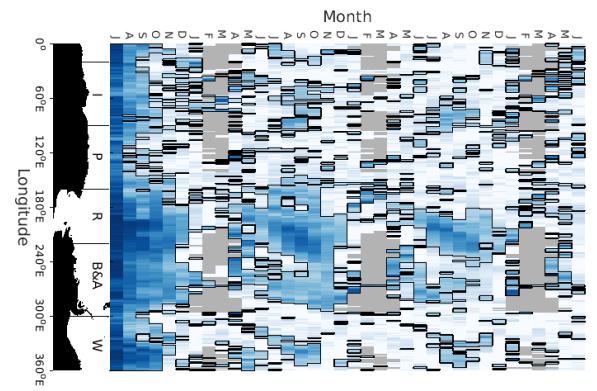

(f) MPI-ESM-LR

Fig. 4 Prognostic potential predictability (PPP) of the ice edge location as a function of longitude and lead time for the six models used. The forecast lead time is from left to right, July 1st corresponding to the start month. Areas in grey represent the longitudes free of sea ice during summer, while areas outlined in black refer to values that are significant at the $95 \%$ level. A map of Antarctica is included in each panel to make the PPP results easier to interpret. The sectors constituting the Southern Ocean, i.e. the Indian Ocean, the Pacific Ocean, the Ross Sea, the Bellingshausen and Amundsen Seas and the Weddell Sea, are denoted by the letters I, P, R, B\&A and $\mathrm{W}$, respectively 
in the supplementary material. It ensues from this additional analysis that the overall behaviour depicted above for the ensemble predictions started on July 1st is still valid. The ice edge location is still not predictable during the summer period, with a noticeable exception for the ensemble predictions initialised on January 1st. From this start month, the ice edge location is predictable during the first months of integration, that is in summer, at the longitudes where summer sea ice persists. As the summer ice edge location becomes unpredictable during the second and third years of prediction, this result is plainly attributed to the direct influence of the initial conditions on the ensemble members evolution. The skill at some lead time is highly dependent on when the forecast is started (skilful PPP values found at longer lead times for predictions started on January 1st). A similar result was found in the Arctic by Day et al (2014b). Nevertheless, the choice of the start month does not affect the predictability reemergence described above. Note that no additional data was provided for EC-Earth2.2, preventing us from checking any improvement with another start month.

The locations where the predictability reemerges vary between the models even if some are shared by several models. For instance, ECHAM6-FESOM, GFDL CM3, HadGEM1.2 and MPI-ESM-LR show predictability in the Ross and Amundsen Seas, ECHAM6-FESOM, GFDL CM3 and MIROC5.2 in the Weddell Sea, GFDL CM3, HadGEM1.2 and MIROC5.2 in the Indian and Pacific Ocean sectors of the Southern Ocean and, finally, GFDL CM3 and MPI-ESM-LR in the Bellingshausen Sea.

The second year of simulation is also characterised by a loss of predictability in summer followed by significant values of PPP in autumn. The predictability patterns look similar to those of the previous year, but with slightly weaker PPP values in almost every location. This weakening causes the predictability to almost completely vanish in HadGEM1.2.

An eastward propagation of the predictability was reported in the CCSM3 model by Holland et al (2013). A similar propagation is observed in ECHAM6-FESOM, GFDL CM3, HadGEM1.2 and MPI-ESM-LR. Figure 4 shows that the eastward propagation mainly occurs in the Ross Sea, the Amundsen and Bellingshausen Seas and in the Weddell Sea. While the eastward propagation was also simulated in the West Pacific sector in CCSM3, only HadGEM1.2 simulates it. Interestingly, MIROC5.2 is the only model not to simulate an eastward propagation of the predictability. This can be understood by looking at the SIE mean states simulated by the models. Figure 1a shows that MIROC5.2 simulates the lower SIE, causing the ice edge to be located close to the continent (see Figure 2). Conversely, the ice edge simulated by the other models is located more northwards. The ice edge in ECHAM6-FESOM, GFDL CM3, HadGEM1.2 and MPI-ESM-LR could consequently be more affected by the prevailing westerly winds, causing its predictability to shift eastwards.

What emerges from Figure 4 is that the ice edge is potentially predictable three years in advance in ECHAM6-FESOM, GFDL CM3, MPI-ESM-LR and, to a lesser extent, HadGEM1.2. The predictability even reaches 3.5 years in MIROC5.2. Nonetheless, this predictability exhibits a wide variation between the seasons and the regions. It appears that the ice edge location cannot be predicted in summer at most locations, while the highest PPP values are found in winter. In addition, the predictability of the ice edge for a given model is confined to the same bands of longitudes throughout the prediction. In the next section, we consider the sources of predictability that cause the above-mentioned behaviour. 
3.2 Predictability of the ocean

The Antarctic sea ice almost entirely disappears during austral summer, which makes it very different to its Arctic counterpart. Apart from HadGEM1.2, Figure 1a shows that all models simulate little sea ice in summer. This near disappearance prevents sea ice from keeping a record of its past conditions after the summer retreat, unlike the Arctic sea ice, where sea ice thickness anomalies provide a source of predictability (e.g., Chevallier and Salas-Mélia (2012); Day et al (2014b)). Moreover, one can presumably expect the little coastal remnants of sea ice (see Figure S2 in the supplementary material) to be primarily affected by unpredictable regional processes, making them unpredictable in summer. Nevertheless, these features do not prevent sea ice from being predictable as soon as it grows during the next season. The fact that the same ice edge reemergence is observed regardless of the start month also supports the weak influence of the summer sea ice state on the winter predictability. It indicates that accurately initialising sea ice in summer is of little importance for its winter evolution. This is in agreement with the study of Guemas et al (2016), who studied the impact of the sea ice initialisation on Antarctic sea ice predictability on seasonal timescales. They found that initialising the winter sea ice conditions from their best possible observational estimate in May does not improve the quality of Antarctic sea ice predictions, suggesting that skilful SIE predictions should not be attributed to the sea ice memory. As the ocean was initialised in May too, this indicates that the ocean initial state prevails in controlling the evolution of the sea ice during the growing season.

As already pointed out by Holland et al (2013) and Zunz et al (2014), the ice edge variations are constrained by the heat anomalies stored in the ocean. However, those anomalies do not remain at the ocean surface. Figure S5 of the supplementary material shows that the PPP applied to the SSTs greatly depends on the season, with highly significant values found in winter and low and generally non-significant values in summer. An examination of Figure 2 reveals that the longitudes for which the SSTs are still predictable in summer are typical of the regions with extensive deep mixed layers areas, probably accounting for the persistence of the SST anomalies at those locations (see Figure 6). We will discuss in the next sections the influence of those regions on the winter-to-winter reemergence of SST anomalies. Consequently, we investigated the role of a thicker oceanic layer, close to the surface, to explain the reemergence of the ice edge predictability.

We computed the PPP of the ocean heat content (OHC) between 0 and $100 \mathrm{~m}$ depth. For a given longitude, the ocean heat content was integrated over latitudes situated between the coast and the northernmost ice edge location found in the control run of each model for each longitude. Figure 5 shows the results for the 36 months (42 for MIROC5.2) of integration for the six models.

Unlike the predictability of the ice edge location, the $\mathrm{OHC}$ is potentially predictable at some longitudes for the whole period of simulation, including the summer months. ECHAM6-FESOM, GFDL CM3, MIROC5.2 and MPI-ESM-LR exhibit well-defined strips of high PPP values. Albeit less pronounced, those strips are also present in HadGEM1.2. Figure 5 and Figure S5 of the supplementary material have been compared, showing no appreciable differences between the positions of the strips of high PPP values for the OHC and the SSTs. Among the models, EC-Earth2.2 is the least predictable, with the $\mathrm{OHC}$ becoming unpredictable after the first five forecast lead months almost everywhere, except in the Weddell Sea sector. The location 


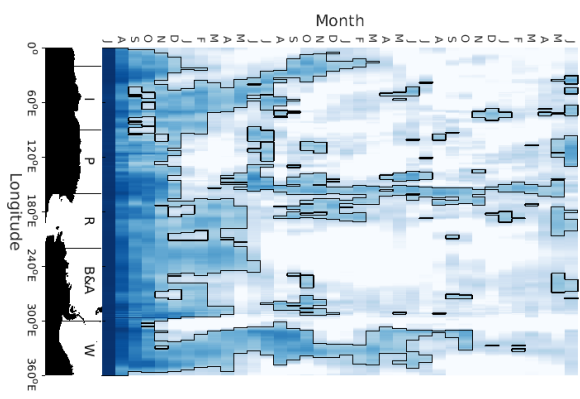

(a) EC-Earth2.2

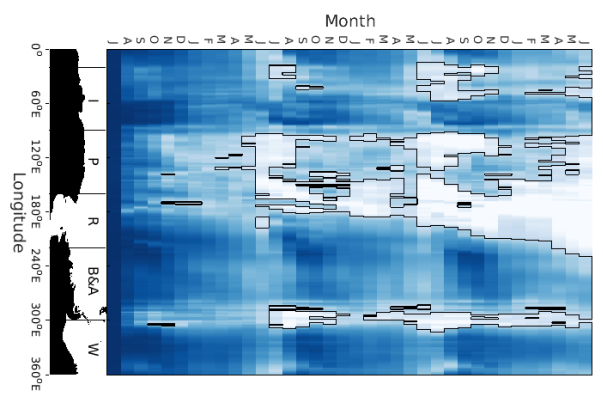

(c) GFDL CM3

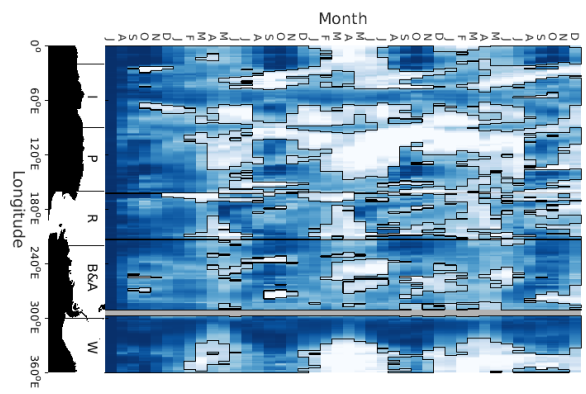

(e) MIROC5.2

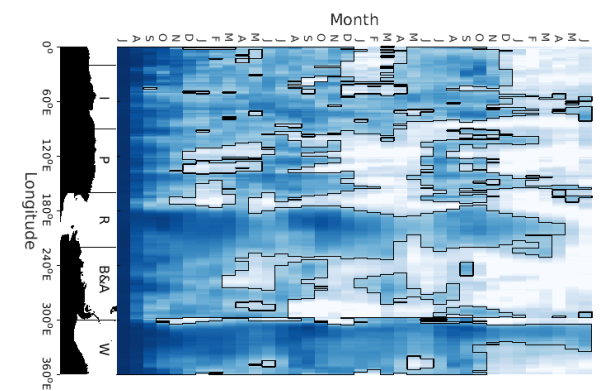

(b) ECHAM6-FESOM

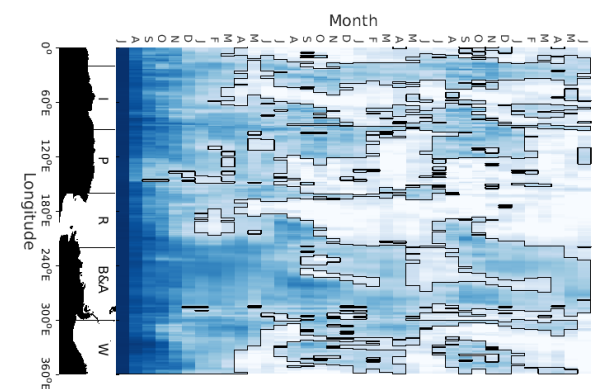

(d) HadGEM1.2

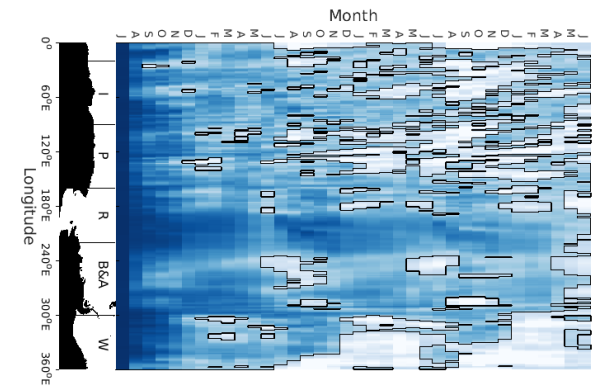

(f) MPI-ESM-LR

Fig. 5 Prognostic potential predictability (PPP) of the ocean heat content computed for the six models between 0 and $100 \mathrm{~m}$ depth and between the coast and the ice edge, as defined in the text. The forecast lead time is from left to right, July 1st corresponding to the start month. Areas outlined in black refer to values that are significant at the $95 \%$ level. As in Figure 4, a map of Antarctica was included in each panel to make the PPP results easier to interpret 
of the strips of high PPP values varies from one model to another, but they share a common property. They match the longitudes where the predictability of the ice edge location is significant. This result highlights the role of the ocean in explaining this predictability. From Figure 5, we clearly identify longitudes for which the ocean behaves in a consistent way. This common behaviour shared by the ensemble members causes the sea ice to be predictable at those longitudes. Since the interactions between the interior of the ocean and the surface are effective during winter months (April to November) and nearly absent during the rest of the year, the predictability of the ice edge location is only significant for this period of the year. Note the westerly propagation of the OHC PPP maxima in the Ross Sea and the Bellingshausen and Amundsen Seas in GFDL CM3 in line with propagation of SIC PPP. A similar, but less pronounced, propagation is also observed in HadGEM1.2 in the same sectors.

\section{Discussion}

\subsection{A mechanism of reemergence}

Alexander and Deser (1995) identified such a winter-to-winter recurrence of SST anomalies in the North Pacific Ocean. This behaviour was attributed to the persistence of ocean temperature anomalies beneath the summer mixed layer. The anomalies at depth reflect the temperature variations occurring at the surface in winter when the mixed layer is deep. They interact with the surface once the mixed layer deepens in autumn. Later on, Hanawa and Sugimoto (2004) carried out a comprehensive study of the World Ocean and found the reemergence of winter SST anomalies in many other locations. More recently, Holland et al (2013) spotted this mechanism in the Southern Ocean and showed that it could potentially contribute to skilful sea ice seasonal forecasts in that region. The mechanism of reemergence of the winter SST anomalies in polar regions is not confined to south polar regions, as it was also reported in the Barents Sea by Bushuk et al (2017), leading to an improvement of sea ice seasonal forecasts in that region.

We tested this mechanism of reemergence for all the models. To do so, we computed from the control simulations the Pearson correlation between the September SSTs and the potential temperatures at depth at different lags. The highest ice edge PPP values found in September account for the choice of this reference month (see Figure 4). Prior to the computation of the correlations, the potential temperatures were averaged over quarters of 20 degrees longitude. Each quarter was further limited to the northernmost ice edge location found for each longitude in the control run. The time series of the averaged temperatures were then detrended for each of the vertical levels and for each of the 12 calendar months. The correlations are illustrated in Figure 6, along with the seasonal cycles of the density-based and temperature-based MLDs. They are respectively estimated with the fixed difference threshold criteria from the near-surface $0.03 \mathrm{~kg} / \mathrm{m}^{3}$ and $0.2{ }^{\circ} \mathrm{C}$. Dong et al (2008) suggested that the shallower of the two MLDs should be employed to estimate the fully homogenized mixed layer. The lag correlation analysis has also been extended to EC-Earth2.2 for comparison.

In September, low surface temperatures and brine rejection associated with sea ice formation cause the mixed layer to deepen. This deepening fosters the interactions between the surface and the interior of the ocean, leading to strong positive corre- 


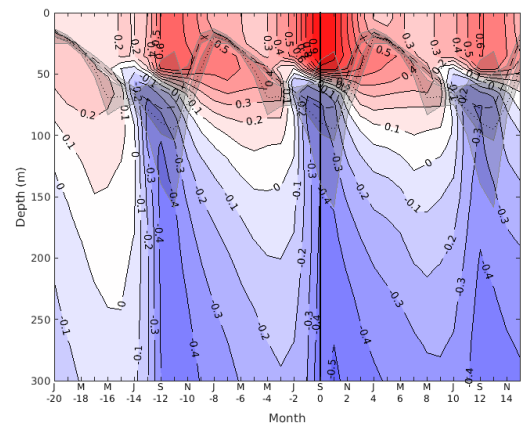

(a) EC-Earth2.2 $\left(340-360^{\circ} \mathrm{E}\right)$

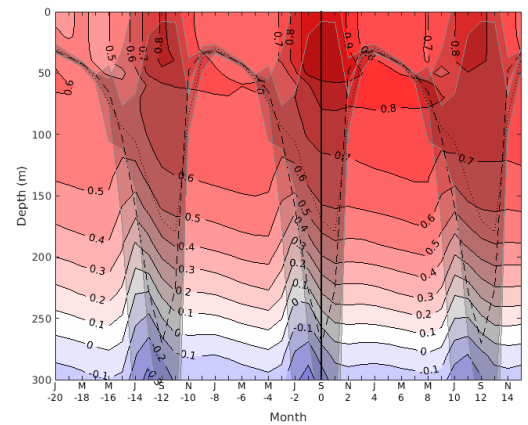

(c) ECHAM6-FESOM $\left(320-340^{\circ} \mathrm{E}\right)$

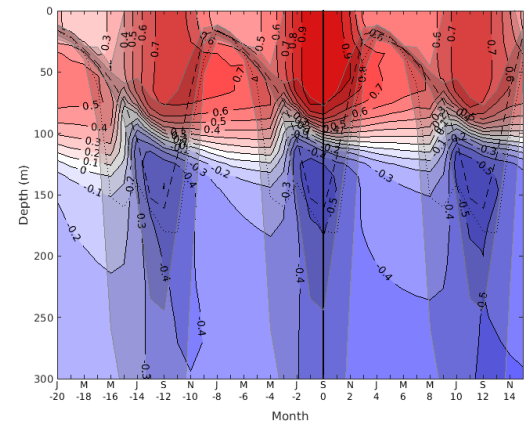

(e) GFDL CM3 $\left(200-220^{\circ} \mathrm{E}\right)$

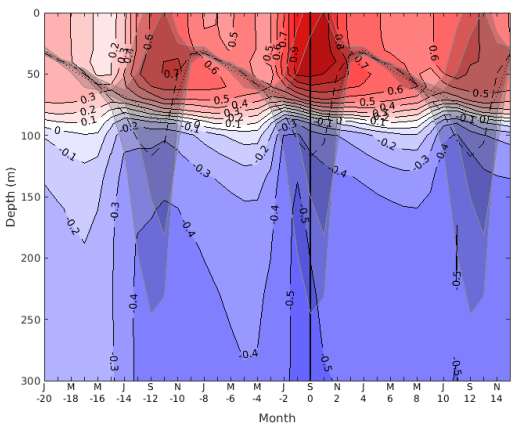

(b) ECHAM6-FESOM $\left(180-200^{\circ} \mathrm{E}\right)$

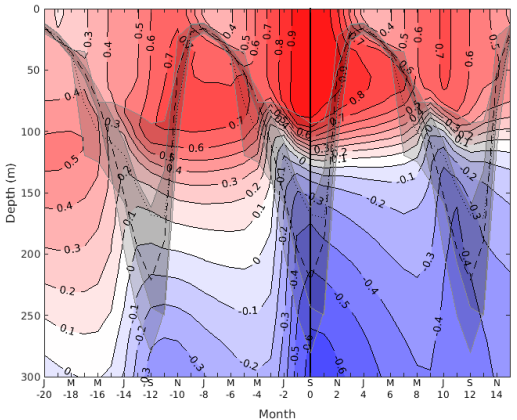

(d) GFDL CM3 $\left(60-80^{\circ} \mathrm{E}\right)$

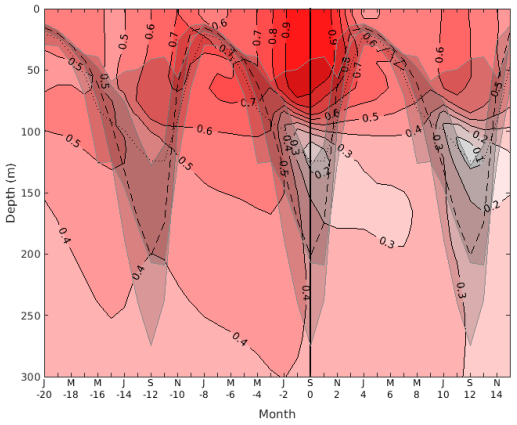

(f) GFDL CM3 $\left(320-340^{\circ} \mathrm{E}\right)$

Fig. 6 Correlation between SSTs in September and potential temperatures at depth at different lags computed from EC-Earth2.2, ECHAM6-FESOM and GFDL CM3 for the regions (mentioned below each figure) where the ice edge location is predictable at least one year ahead. The thick vertical black line marks the reference month, i.e. September, for the lagged correlations. The density-based (temperature-based) MLD seasonal cycle is represented by the black dashed (dotted) line. The shaded region around the curves represents the corresponding MLD standard deviations 


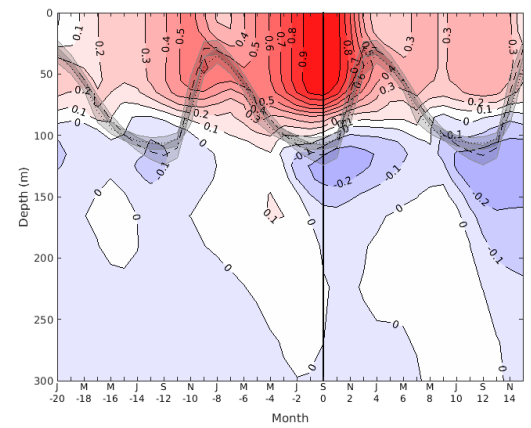

(g) HadGEM1.2 $\left(60-80^{\circ} \mathrm{E}\right)$

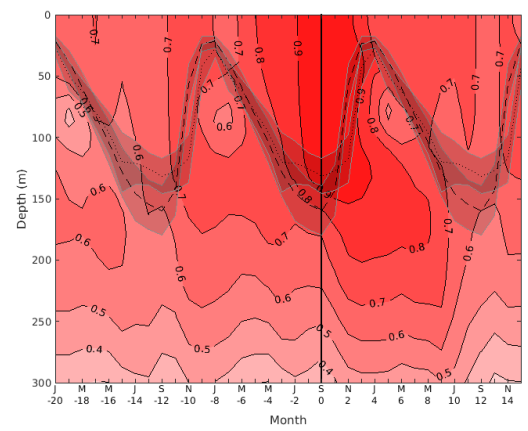

(i) MIROC5-2 $\left(40-60^{\circ} \mathrm{E}\right)$

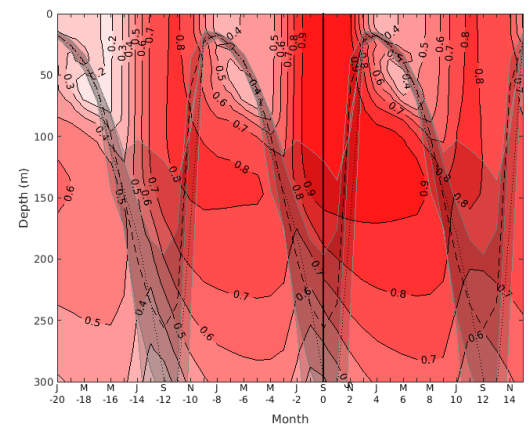

(k) MIROC5-2 $\left(320-340^{\circ} \mathrm{E}\right)$

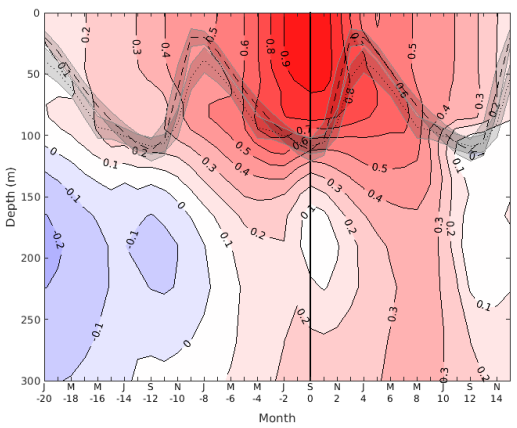

(h) HadGEM1.2 $\left(240-260^{\circ} \mathrm{E}\right)$

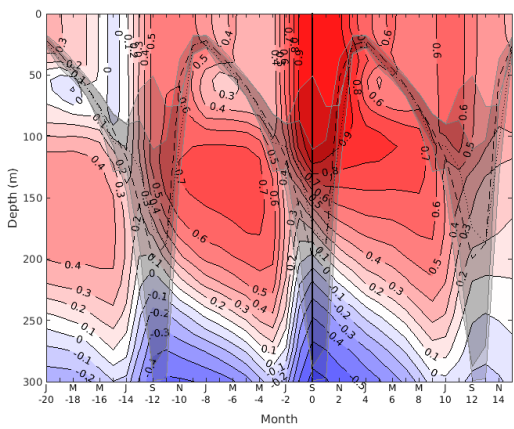

(j) MIROC5-2 $\left(140-160^{\circ} \mathrm{E}\right)$

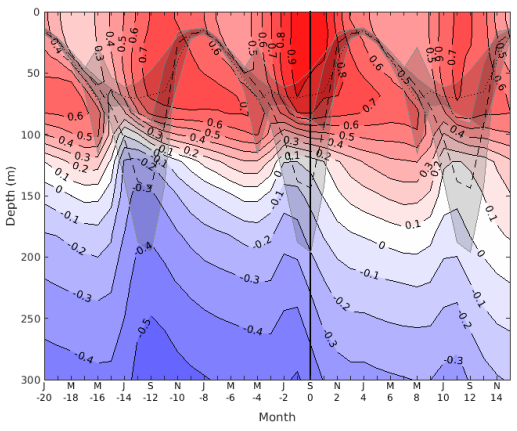

(1) MPI-ESM-LR $\left(200-220^{\circ} \mathrm{E}\right)$

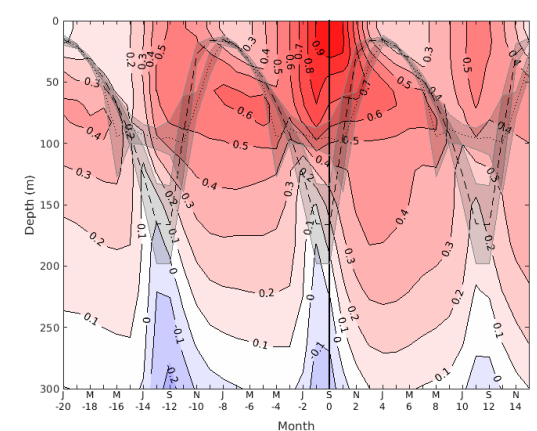

(m) MPI-ESM-LR $\left(320-340^{\circ} \mathrm{E}\right)$

Fig. 6 (cont.) Same as before, but for HadGEM1.2, MIROC5.2 and MPI-ESM-LR 
lations through the mixed layer. This situation persists until the end of the winter when the sea ice starts retreating. The mixed layer then shoals, and the anomalies at depth are isolated from the surface during summer. When the mixed layer deepens again during the next winter, those temperature anomalies resurface and influence the ice advance. By this mechanism we can explain how ice edge variations at the end of the winter, which directly impact the SST, influence the ice edge location the following year. The study of the reemergence of the SST anomalies reveals large longitudinal variations of the performance of the mechanism within a given model. We noticed that the SST anomalies are closely tied to the seasonal cycle of the mixed layer. Winter SST anomalies are more efficiently preserved below the surface in summer in the regions/models which show deep winter mixed layers. This result agrees with the study of Dommenget and Latif (2002) carried out at midlatitudes. They found that the SST variability is strongly influenced by the MLD variability and concluded that a better representation of the MLD in models at those latitudes is therefore suited to improve the seasonal-to-interannual predictability of the SST anomalies.

Our model intercomparison confirms the prime importance of the SST reemergence mechanism in the Antarctic as it is observed in the five models that show a reemergence of the predictability of the ice edge location. It also reveals that the mechanism acts almost everywhere the ice edge is predictable (see Figure 6) and that the mechanism is missing at longitudes where the ice edge location cannot be predicted (not shown). However, we were not able to clearly identify the reemergence of the SST anomalies as the source of the ice edge predictability for ECHAM6-FESOM and GFDL CM3 in the Bellingshausen and Admunsen Seas. Interestingly, those regions are characterised by an eastward shift of the ice edge predictability originating from the Ross Sea (see Figure 4). This possibly indicates that the ice edge in those models is more controlled by the horizontal advection of ocean temperature anomalies coming from the Ross Sea or by the atmosphere. We also found that the September SST anomalies are likely to persist at the surface throughout the summer in the sectors where deep ocean convection events occur. This is in agreement with Figure S5 of the supplementary material. Deep convection events are responsible for the persistence of those temperature anomalies, due to an efficient mixing through the water column and an upward flow of warmer water layers to the surface. The influence of those events on the persistence of September SSTs can be appreciated by comparing Figures 6 and 7. In the Bellingshausen and Admunsen Seas too, the September SST anomalies persist at the surface in HadGEM1.2. As these anomalies are efficiently retained beneath the summer mixed layer, the persistence at the surface possibly masked the reemergence mechanism. Nevertheless, the source of that persistence remains unclear. It cannot be accounted for by deep convection events, as no such event was detected in this sector (see Figure 3).

In the following section, we investigate the role of the MLD in explaining the longitudinal variations of the performance of the mechanism of reemergence presented here.

\subsection{The role of the mixed layer}

The depth at which the temperature anomalies are stored is typical of the Winter Water depth range. This seasonal subsurface layer is the remaining part of the previ- 
ous winter mixed layer. It resides between the shallow summer mixed layer and the permanent pycnocline. This layer is isolated from the surface in summer by strong thermal and salinity gradients. Although this thin layer of relatively cold water lies on top of warm and salty waters (Circumpolar Deep Water), the salinity gradient is strong enough to stabilize the water column. The existence of this seasonal layer was for instance reported near the Wilkes Land coast of Antarctica (Wong and Riser (2011)) and in the Enderby Basin (Park et al (1998)). The information about the winter sea surface properties is expected to remain in this layer until the seasonal stratification is eroded. Depending on the model, the entrainment of the Winter Water to the mixed layer, subsequent to the erosion of the stratification, occurs in April or May. This month coincides with the reemergence of the ice edge predictability discussed above (see Figure 4).

Based on different datasets, Timlin et al (2002) and Hanawa and Sugimoto (2004) found in non-polar oceans that a large seasonal variation of the MLD is a necessary condition for the reemergence of winter SST anomalies. Figure 2 (right column) brings out the differences in the amplitude of the MLD seasonal cycle simulated by the six models. Among the models, EC-Earth2.2 is the one that simulates the smallest seasonal variations of the MLD in the regions of the Southern Ocean seasonally covered by sea ice. This contrasts with the strong seasonal variations of the MLD simulated in the open ocean by ECHAM6-FESOM, GFDL CM3, HadGEM1.2, MIROC5.2 and MPI-ESM-LR. The amplitude of the MLD seasonal cycle simulated by those models in the open ocean can be up to five times larger than the observations (Figure 2). This misrepresentation of the amplitude of the MLD seasonal cycle is due to a biased high winter MLD. As EC-Earth2.2 does not exhibit any reemergence of the predictability of the ice edge location and the predictability of the ice edge location in the other models is confined to the longitudes which hold the deepest winter mixed layers in the open ocean, this suggests that a sufficiently strong MLD seasonal cycle is required to efficiently store the winter SST anomalies at depth during the whole summer. As a result, the duration of sea ice potential predictability may be linked to the seasonal amplitude of MLD.

We already mentioned in Section 2.2.2 that the MLDs simulated in the Ross and Weddell Seas significantly differ from the observations for ECHAM6-FESOM, GFDL CM3, HadGEM1.2, MIROC5.2 and MPI-ESM-LR. The simulated winter MLD in these two places is higher than in the rest of the Southern Ocean. Those unrealistic deep mixed layers originate from deep convection. The regions where deep convection is likely to occur are illustrated in Figure 3. We expect anomalous convection in the open ocean to promote significant September-to-September SST correlations. To verify this, we isolated the control run years for which no anomalous convection events happen and repeat the lag correlation analysis for the selected years.

The convective years were removed according to the arbitrary criterion MLD > $500 \mathrm{~m}$. However, this criterion was sometimes either too restrictive or not restrictive enough depending on the models and regions. A too restrictive criterion means that most of the control run years are disregarded. It is therefore impossible to study the impact of anomalous convection events. This situation arose for HadGEM1.2 between 60 and $80^{\circ} \mathrm{E}$ and MIROC5-2 between 40 and $60^{\circ} \mathrm{E}$. Conversely, a not too restrictive criterion implies that not many years of the control run (even none) are removed. In that case, we substituted it for the more convenient MLD $>1000 \mathrm{~m}$ criterion. Note that this last criterion was still not too restrictive for GFDL CM3 between 60 and $80^{\circ} \mathrm{E}$. For the regions studied in Figure 6, we decided for each region 
to remove a year of the control simulation if the MLD criterion was met for at least one of the grid points belonging to that region and one of the three winter months July, August and September. Besides, we also removed the year which directly follows an anomalous convection event to avoid undesired subsequent deep convection effects. We also make sure not to perform the lagged correlations over a temporally discontinuous dataset. We thus only considered the true consecutive years among the selected years. Results are shown in Figure 7. It can be seen from this figure that the correlations consistently weaken for all the models. This suggests that the anomalous convection events occurring in the models sustain the reemergence of winter SST anomalies. In the case of ECHAM6-FESOM, winter SST anomalies between two consecutive years become uncorrelated. This implies that the resulting ice edge predictability for this model only comes from its inability to correctly simulate mixed layers in the Southern Ocean. Although the anomalous convection events in the open ocean for EC-Earth2.2 are too sparse in time to efficiently promote sea ice predictability, we also noticed that the correlations of September-to-September SSTs become weak in the Weddell Sea once the anomalous convection years are removed. Interestingly, HadGEM1.2 is the only model simulating deep open ocean convection with no marked reemergence of the winter SST anomalies associated to it (not shown). This could possibly stems from the area over which the lag correlation analysis is performed. As can be inferred from Figure 2 and 3, the regions which hold deep open ocean convection in HadGEM1.2, i.e. the quarters $300-320^{\circ} \mathrm{E}$ and $320-340^{\circ} \mathrm{E}$, also include areas where the MLD never exceeds $50 \mathrm{~m}$ on average near the ice edge. We thus expect those latter regions to blur the temperature signal.

We also probed the evidence of an impact of deep convection events on the predictability of the ice edge location by applying the PPP to each start date separately rather than to all start dates taken together. It results from this analysis that the ensemble predictions which coincide with one or multiple deep convection event(s) display higher PPP values. This situation was reported in ECHAM6-FESOM for the year 3697 and in MPI-ESM-LR for the year 2263, as shown in Figure 8. Unfortunately, it was not possible to assess the impact of deep convection on the predictability of the ice edge location for GFDL CM3, HadGEM1.2 and MIROC5.2 since those models deeply convect almost all the years of the control run. As a consequence, no significant PPP differences were detected between the ensembles belonging to those three models. Although the predictability results of each individual ensemble are not statistically robust due to the limited number of ensemble members, Figure 8 suggests that capturing deep convection events is important to achieve skilful sea ice prediction.

\section{Summary and conclusions}

In this study, we have examined the initial-value predictability of the Antarctic sea ice on seasonal-to-interannual timescales. This first model intercomparison aimed at identifying in a systematic way the attributes of the sea ice predictability inherent to GCMs in the Antarctic and understand the origin of that predictability. To achieve this objective, we considered idealised ensemble experiments generated by six GCMs. As compared with real ensemble experiments, idealised experiments give a clue to the predictability that could be achieved when forecasting the real climate without being limited by initialisation shocks due to model biases and sparse observations. 


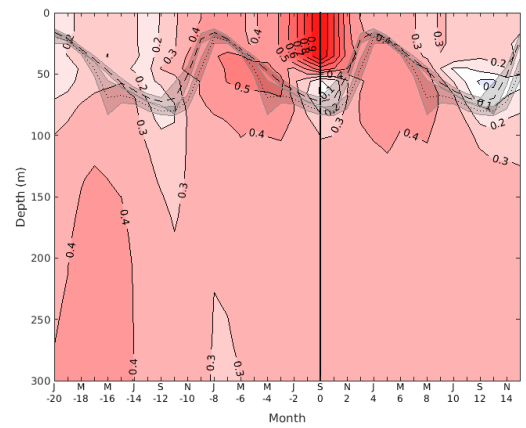

(a) EC-Earth2.2 $\left(340-360^{\circ} \mathrm{E}\right)$ MLD > $500 \mathrm{~m}(155)$

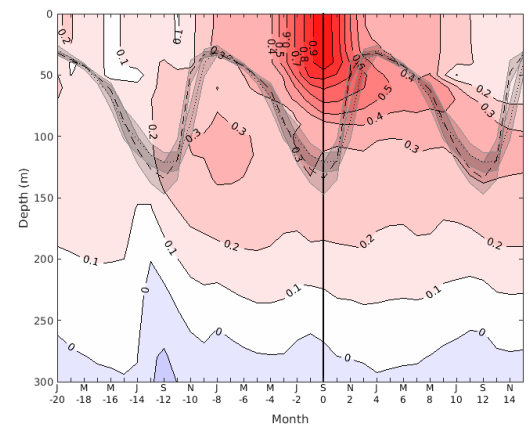

(c) ECHAM6-FESOM $\left(320-340^{\circ} \mathrm{E}\right)$ MLD > $1000 \mathrm{~m}(123)$

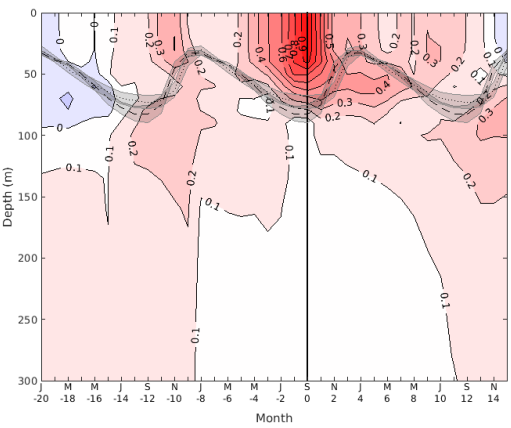

(b) ECHAM6-FESOM $\left(180-200^{\circ} \mathrm{E}\right)$ $\mathrm{MLD}>500 \mathrm{~m}(75)$

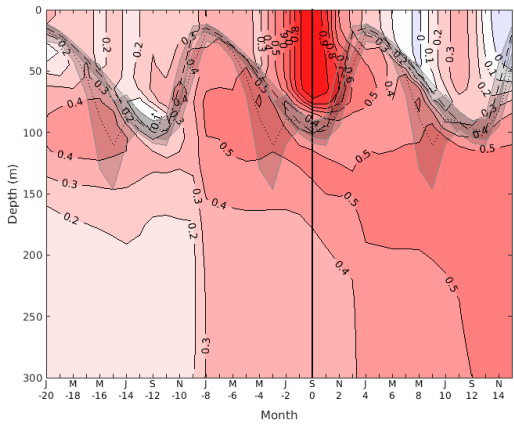

(d) GFDL CM3 $\left(200-220^{\circ} \mathrm{E}\right)$ $\mathrm{MLD}>500 \mathrm{~m}(33)$

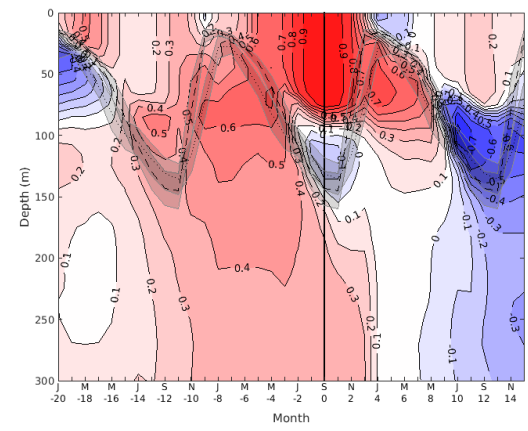

(e) GFDL CM3 $\left(320-340^{\circ} \mathrm{E}\right)$ MLD > $500 \mathrm{~m}(15)$

Fig. 7 Correlation between SSTs in September and potential temperatures at depth at different lags computed from EC-Earth2.2, ECHAM6-FESOM and GFDL CM3 for the regions (mentioned below each figure) where the ice edge location is predictable at least one year ahead. The thick vertical black line marks the reference month, i.e. September, for the lagged correlations. Temperature time series are limited to the years for which no deep convection events happen. The criterion used to identify those events and the number of years used to perform the lagged correlations (in parentheses) are mentioned below each figure. The density-based MLD seasonal cycle is shown with the black dashed line, while the temperature-based MLD seasonal cycle is shown with the dotted line. The shaded region around the curves represents the corresponding MLD standard deviations 


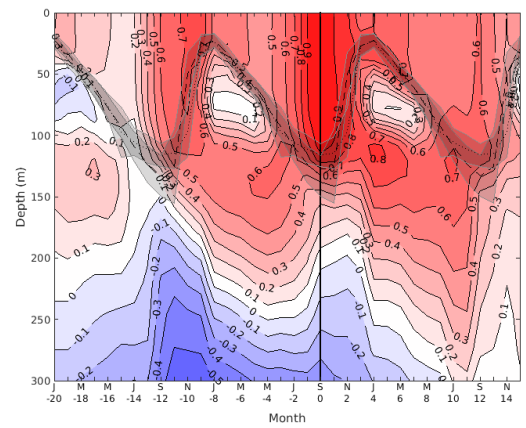

(f) MIROC5-2 $\left(140-160^{\circ} \mathrm{E}\right)$ MLD > $1000 \mathrm{~m}$ (11)

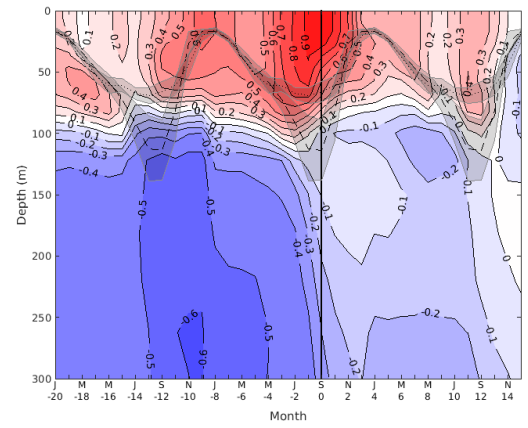

(h) MPI-ESM-LR $\left(200-220^{\circ} \mathrm{E}\right)$ MLD > 500 m (31)

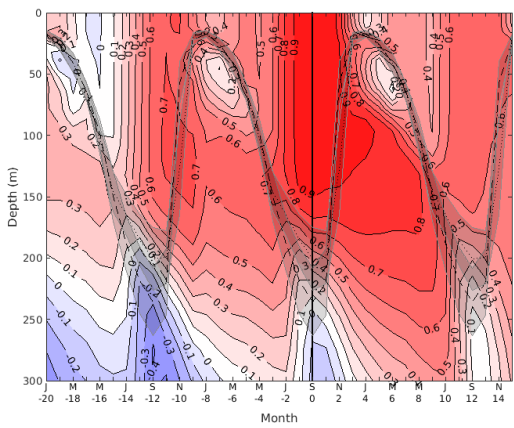

(g) MIROC5-2(320-340 $\left.{ }^{\circ} \mathrm{E}\right)$ MLD > $1000 \mathrm{~m} \mathrm{(17)}$

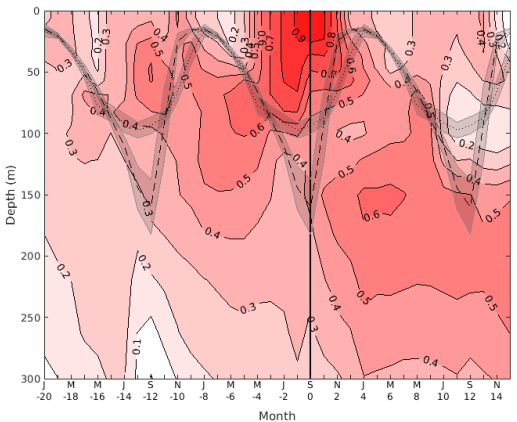

(i) MPI-ESM-LR $\left(320-340^{\circ} \mathrm{E}\right)$ MLD > $1000 \mathrm{~m} \mathrm{(28)}$

Fig. 7 (cont.) Same as before, but for MIROC5.2 and MPI-ESM-LR

These are two major obstacles to the achievement of skilful real Antarctic sea ice predictions.

We assessed the benefit of a perfect knowledge of the initial conditions on the ice edge location using the PPP metric. We found that the predictability quickly falls down after the first lead months, except at some locations where it persists until the end of the year (November/December). All the models then exhibit a complete loss of the predictability in early spring at most locations. The ice retreat acts like a natural barrier for predicting the ice edge location in spring and summer. The little predictive skill found for the summer sea ice contrasts with the Arctic, where sea ice thickness anomalies provide a source of predictability (Blanchard-Wrigglesworth et al (2011); Chevallier and Salas-Mélia (2012); Day et al (2014a)). For five of the six models included in this study, we recovered significant PPP values around May once the sea ice grows. Unlike the other models, EC-Earth2.2 does not exhibit a clear reemergence of the predictability. Finally, the predictability of the ice edge location behaves similarly in the second and third years of integration despite weaker PPP 


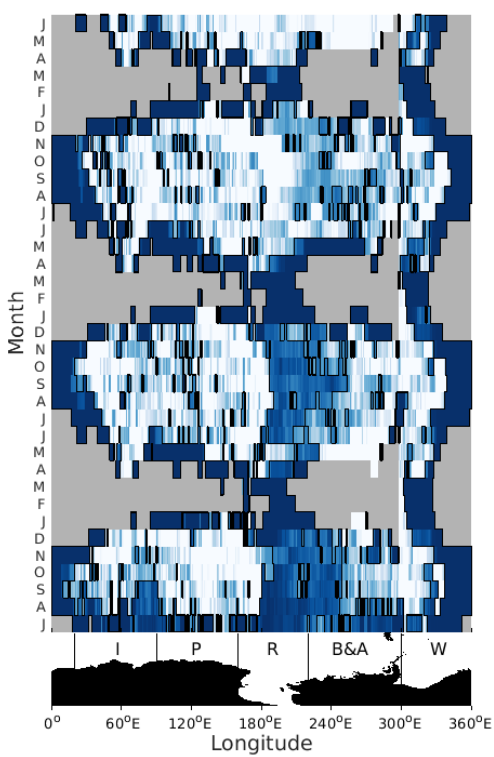

(a) ECHAM6-FESOM

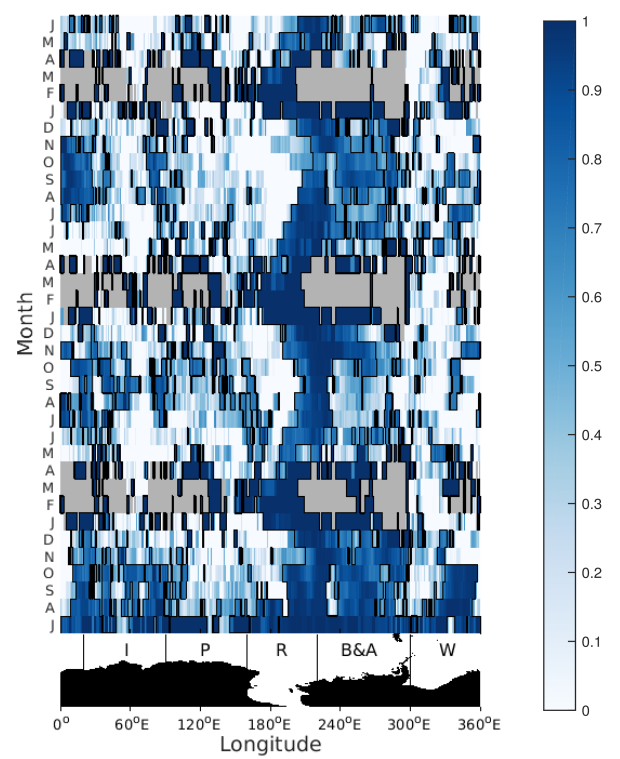

(b) MPI-ESM-LR

Fig. 8 Prognostic potential predictability (PPP) of the ice edge location as a function of longitude and lead time computed for an ensemble which coincides with a deep convection event for ECHAM6-FESOM (year 3697) and MPI-ESM-LR (year 2263). The start month, July 1st, is displayed at the bottom left of each figure. Areas in grey represent the longitudes free of sea ice during summer, while areas outlined in black refer to values that are significant at the $95 \%$ level. As in Figure 4, a map of Antarctica was included in each panel to make the PPP results easier to interpret

values. Regardless of the start month used to initialise the prediction, we do find a reemergence of the predictability of the ice edge location.

The austral summer leaves the ocean with almost no sea ice. Therefore summer sea ice conditions cannot be invoked to explain the reemergence of the predictability between two successive winters. Instead, the ocean acts as a source of memory of previous sea ice conditions, with SSTs strongly influenced by the presence of sea ice. Due to strong mixing in winter, the temperature anomalies at the surface extend through the base of the mixed layer. As the mixed layer shrinks from spring, the temperature anomalies are isolated from the surface and are reentrained into the mixed layer when it deepens again the following autumn. We showed that the effectiveness of this mechanism relies on sufficiently large variations of the MLD seasonal cycle. Among the six models used, EC-Earth2.2 simulates the smallest amplitude of the MLD seasonal cycle, hence the limited potential predictability of the ice edge location found for this model. A similar mechanism of reemergence was found by Bushuk et al (2017) in the Barents Sea. This mechanism of predictability also bears some similarity to the mechanism operating in Arctic regions described by Blanchard-Wrigglesworth et al (2011), where the persistence of SST anomalies in the melt season directly influence the ice growth next season. 
The ice edge predictability reemergence does not occur at all longitudes, but it is rather limited to the longitudes which host the deepest mixed layers. We noticed that the predictability in the Ross and Weddell Seas outperforms the predictability in the other basins of the Southern Ocean. The high potential predictability results achieved in these two regions stem from the anomalous convection events occurring there. It was shown that the absence of such events systematically reduces the September-toSeptember SSTs correlations. It even leads to no correlation for ECHAM6-FESOM. A detailed analysis of each ensemble also pointed out the influence of those extreme events on the ice edge predictability. We found for ECHAM6-FESOM and MPIESM-LR two ensembles whose start dates coincide with at least one deep convection event. The computation of the associated PPP revealed higher predictive skill at the longitudes where it occurred compared with the other ensembles. Accordingly, caution must be exercised in interpreting the magnitude of the skill using a multiensemble approach in order to evaluate the potential predictability of the sea ice. As the predictability is inflated by occasional deep convection events, incorrectly sampling the ocean state (through the ensemble start dates) could lead to an overestimation of the ice edge predictability. This issue raises important questions about the design of future sea ice predictability experiments, and especially, how the start dates should be selected from the control simulation. Future ensemble experiments dedicated to the prediction of the Antarctic sea ice should address, more closely, the oceanic state dependence of the predictability.

It is worth emphasising that our predictability study refers to potential predictability, that is the predictability that we would get if dealing with perfectly known initial conditions and unbiased models. Although the mechanism described in this study is likely to take place in the Southern Ocean, there is some evidence that models would overestimate the predictability achievable from observations for two reasons. The first one is related to the mean ocean MLDs simulated by the models. The climatology of Pellichero et al (2017) shows that the observed MLD in the marginal sea ice zone is consistently smaller than the one simulated by the models that experience a clear reemergence of the predictability of the ice edge location. The second reason relates to the deep convection events. They are hardly ever observed in the open ocean, but we expect them to play a key role in the reemergence of SST anomalies. For those reasons, we expect the comparison to observations to substantially degrade the potential predictability results discussed here. The promising results derived from this idealised experimental set up should thus be interpreted with care. Nonetheless, this study provides some informed perspectives on what can reasonably be expected from real ensemble predictions of the Antarctic sea ice. A better representation of the Southern Ocean in climate models should be regarded as a priority if one wants to advance our understanding of the Antarctic sea ice, especially its variability, emphasising the critical need for a comprehensive set of ocean observations with a fully spatial coverage.

Acknowledgements We thank the two referees for their very helpful comments on an earlier version of this manuscript.

Hugues Goosse is Research Director within the Fonds National de la Recherche Scientifique (F.R.S.-FNRS-Belgium). 


\section{References}

Alexander MA, Deser C (1995) A mechanism for the recurrence of wintertime midlatitude SST anomalies. Journal of Physical Oceanography 25(1):122-137, DOI 10.1175/1520-0485(1995)025<0122:amftro > 2.0.co;2

Armour KC, Eisenman I, Blanchard-Wrigglesworth E, McCusker KE, Bitz CM (2011) The reversibility of sea ice loss in a state-of-the-art climate model. Geophysical Research Letters 38(16):n/a-n/a, DOI 10.1029/2011gl048739

Barthélemy A, Fichefet T, Goosse H, Madec G (2015) Modeling the interplay between sea ice formation and the oceanic mixed layer: Limitations of simple brine rejection parameterizations. Ocean Modelling 86:141-152, DOI 10.1016/j.ocemod. 2014.12.009

Behrens E, Rickard G, Morgenstern O, Martin T, Osprey A, Joshi M (2016) Southern Ocean deep convection in global climate models: a driver for variability of subpolar gyres and Drake Passage transport on decadal timescales. Journal of Geophysical Research: Oceans 121(6):3905-3925, DOI 10.1002/2015jc011286

Bintanja R, van Oldenborgh GJ, Drijfhout SS, Wouters B, Katsman CA (2013) Important role for ocean warming and increased ice-shelf melt in Antarctic sea-ice expansion. Nature Geoscience 6(5):376-379, DOI 10.1038/ngeo1767, URL https: //doi.org/10.1038/ngeo1767

Bitz CM, Polvani LM (2012) Antarctic climate response to stratospheric ozone depletion in a fine resolution ocean climate model. Geophysical Research Letters 39(20):n/a-n/a, DOI 10.1029/2012GL053393, URL http://dx.doi.org/10.1029/ 2012GL053393, 120705

Blanchard-Wrigglesworth E, Armour KC, Bitz CM, DeWeaver E (2011) Persistence and inherent predictability of Arctic sea ice in a GCM ensemble and observations. Journal of Climate 24(1):231-250, DOI 10.1175/2010jcli3775.1

de Boyer Montégut C (2004) Mixed layer depth over the global ocean: an examination of profile data and a profile-based climatology. Journal of Geophysical Research 109(C12), DOI 10.1029/2004jc002378

Bushuk M, Msadek R, Winton M, Vecchi GA, Gudgel R, Rosati A, Yang X (2017) Skillful regional prediction of Arctic sea ice on seasonal timescales. Geophysical Research Letters DOI 10.1002/2017gl073155

Chevallier M, Salas-Mélia D (2012) The role of sea ice thickness distribution in the Arctic sea ice potential predictability: a diagnostic approach with a coupled GCM. Journal of Climate 25(8):3025-3038, DOI 10.1175/jcli-d-11-00209.1

Comiso JC, Gersten RA, Stock LV, Turner J, Perez GJ, Cho K (2017) Positive trend in the Antarctic sea ice cover and associated changes in surface temperature. Journal of Climate 30(6):2251-2267, DOI 10.1175/JCLI-D-16-0408.1, URL https: //doi.org/10.1175/JCLI-D-16-0408.1, https://doi.org/10.1175/JCLI-D-16-0408.1

Day JJ, Hawkins E, Tietsche S (2014a) Will Arctic sea ice thickness initialization improve seasonal forecast skill? Geophysical Research Letters 41(21):7566-7575, DOI 10.1002/2014GL061694, URL http://dx.doi.org/10.1002/2014GL061694

Day JJ, Tietsche S, Hawkins E (2014b) Pan-Arctic and regional sea ice predictability: Initialization month dependence. Journal of Climate 27(12):4371-4390, DOI 10. $1175 /$ jcli-d-13-00614.1

Day JJ, Tietsche S, Collins M, Goessling HF, Guemas V, Guillory A, Hurlin WJ, Ishii M, Keeley SPE, Matei D, Msadek R, Sigmond M, Tatebe H, Hawkins E (2016) The Arctic Predictability and Prediction on Seasonal-to-Interannual TimEscales 
(apposite) data set version 1. Geoscientific Model Development 9(6):2255-2270, DOI 10.5194/gmd-9-2255-2016, URL http://www.geosci-model-dev.net/9/2255/ 2016/

Ding Q, Steig EJ, Battisti DS, Küttel M (2011) Winter warming in West Antarctica caused by central tropical Pacific warming. Nature Geoscience 4(6):398-403, DOI 10.1038/ngeo1129, URL https://doi.org/10.1038/ngeo1129

Dommenget D, Latif M (2002) Analysis of observed and simulated SST spectra in the midlatitudes. Climate Dynamics 19(3-4):277-288, DOI 10.1007/s00382-002-0229-9

Dong S, Sprintall J, Gille ST, Talley L (2008) Southern Ocean mixed-layer depth from Argo float profiles. Journal of Geophysical Research 113(C6), DOI 10.1029/ $2006 \mathrm{jc} 004051$

Donner LJ, Wyman BL, Hemler RS, Horowitz LW, Ming Y, Zhao M, Golaz JC, Ginoux P, Lin SJ, Schwarzkopf MD, Austin J, Alaka G, Cooke WF, Delworth TL, Freidenreich SM, Gordon CT, Griffies SM, Held IM, Hurlin WJ, Klein SA, Knutson TR, Langenhorst AR, Lee HC, Lin Y, Magi BI, Malyshev SL, Milly PCD, Naik V, Nath MJ, Pincus R, Ploshay JJ, Ramaswamy V, Seman CJ, Shevliakova E, Sirutis JJ, Stern WF, Stouffer RJ, Wilson RJ, Winton M, Wittenberg AT, Zeng F (2011) The dynamical core, physical parameterizations, and basic simulation characteristics of the atmospheric component AM3 of the GFDL global coupled model CM3. Journal of Climate 24(13):3484-3519, DOI 10.1175/2011jcli3955.1

EUMETSAT (2015) Ocean and sea ice satelitte application facility. global sea ice concentration climate data records 1978-2015 (v1.2, 2015). Online, DOI 10.15770/ EUM_SAF_OSI_000110.15770/EUM_SAF_OSI_0005, norwegian and Danish Meteorological Institutes

Ferreira D, Marshall J, Bitz CM, Solomon S, Plumb A (2015) Antarctic ocean and sea ice response to ozone depletion: A two-time-scale problem. Journal of Climate 28(3):1206-1226, DOI 10.1175/JCLI-D-14-00313.1, URL https://doi.org/ 10.1175/JCLI-D-14-00313.1, https://doi.org/10.1175/JCLI-D-14-00313.1

Goosse H, Zunz V (2014) Decadal trends in the Antarctic sea ice extent ultimately controlled by ice-ocean feedback. The Cryosphere 8(2):453-470, DOI 10.5194/tc8-453-2014, URL http://www.the-cryosphere.net/8/453/2014/

Gordon AL, Taylor HW (1975) Seasonal change of Antarctic sea ice cover. Science 187(4174):346-347, DOI 10.1126/science.187.4174.346

Griffies SM, Winton M, Donner LJ, Horowitz LW, Downes SM, Farneti R, Gnanadesikan A, Hurlin WJ, Lee HC, Liang Z, Palter JB, Samuels BL, Wittenberg AT, Wyman BL, Yin J, Zadeh N (2011) The GFDL CM3 coupled climate model: characteristics of the ocean and sea ice simulations. Journal of Climate 24(13):35203544, DOI 10.1175/2011jcli3964.1

Guemas V, Chevallier M, Déqué M, Bellprat O, Doblas-Reyes F (2016) Impact of sea ice initialization on sea ice and atmosphere prediction skill on seasonal timescales. Geophysical Research Letters 43(8):3889-3896, DOI 10.1002/2015GL066626, URL http://dx.doi.org/10.1002/2015GL066626

Hanawa K, Sugimoto S (2004) 'reemergence' areas of winter sea surface temperature anomalies in the world's oceans. Geophysical Research Letters 31(10):n/a-n/a, DOI 10.1029/2004GL019904, URL http://dx.doi.org/10.1029/2004GL019904, 110303

Haumann FA, Notz D, Schmidt H (2014) Anthropogenic influence on recent circulation-driven Antarctic sea ice changes. Geophysical Research Letters 41(23):8429-8437, DOI 10.1002/2014GL061659, URL http://dx.doi.org/10.1002/ 
2014GL061659, 2014GL061659

${ }_{855}$ Hawkins E, Tietsche S, Day JJ, Melia N, Haines K, Keeley S (2016) Aspects of designing and evaluating seasonal-to-interannual Arctic sea-ice prediction systems. Quarterly Journal of the Royal Meteorological Society 142(695):672-683, DOI 10.1002/qj.2643, URL http://dx.doi.org/10.1002/qj.2643

Hazeleger W, Wang X, Severijns C, Ştefănescu S, Bintanja R, Sterl A, Wyser K, Semmler T, Yang S, van den Hurk B, van Noije T, van der Linden E, van der Wiel K (2011) EC-Earth V2.2: description and validation of a new seamless earth system prediction model. Climate Dynamics 39(11):2611-2629, DOI 10.1007/s00382-0111228-5

Heuzé C, Heywood KJ, Stevens DP, Ridley JK (2013) Southern Ocean bottom water characteristics in CMIP5 models. Geophysical Research Letters 40(7):1409-1414, DOI 10.1002/grl.50287

Holland MM, Blanchard-Wrigglesworth E, Kay J, Vavrus S (2013) Initial-value predictability of Antarctic sea ice in the Community Climate System Model 3. Geophysical Research Letters 40(10):2121-2124, DOI 10.1002/grl.50410, URL http://dx.doi.org/10.1002/grl.50410

Holland PR, Kwok R (2012) Wind-driven trends in Antarctic sea-ice drift. Nature Geosci 5(12):872-875, DOI 10.1038/ngeo1627, URL http://dx.doi.org/10.1038/ ngeo1627

Holte J, Talley L (2009) A new algorithm for finding mixed layer depths with applications to Argo data and Subantarctic Mode Water formation*. Journal of Atmospheric and Oceanic Technology 26(9):1920-1939, DOI 10.1175/2009jtecho543.1

Ivanova N, Pedersen LT, Tonboe RT, Kern S, Heygster G, Lavergne T, Sørensen A, Saldo R, Dybkjær G, Brucker L, Shokr M (2015) Inter-comparison and evaluation of sea ice algorithms: towards further identification of challenges and optimal approach using passive microwave observations. The Cryosphere 9(5):1797-1817, DOI 10.5194/tc-9-1797-2015, URL https://www.the-cryosphere. net $/ 9 / 1797 / 2015 /$

Johns TC, Durman CF, Banks HT, Roberts MJ, McLaren AJ, Ridley JK, Senior CA, Williams KD, Jones A, Rickard GJ, Cusack S, Ingram WJ, Crucifix M, Sexton DMH, Joshi MM, Dong BW, Spencer H, Hill RSR, Gregory JM, Keen AB, Pardaens AK, Lowe JA, Bodas-Salcedo A, Stark S, Searl Y (2006) The new Hadley Centre climate model (HadGEM1): evaluation of coupled simulations. Journal of Climate 19(7):1327-1353, DOI 10.1175/jcli3712.1

Jungclaus JH, Fischer N, Haak H, Lohmann K, Marotzke J, Matei D, Mikolajewicz U, Notz D, von Storch JS (2013) Characteristics of the ocean simulations in the Max Planck Institute Ocean Model (MPIOM) the ocean component of the MPIEarth system model. Journal of Advances in Modeling Earth Systems 5(2):422446, DOI 10.1002/jame.20023

Koenigk T, Mikolajewicz U (2008) Seasonal to interannual climate predictability in mid and high northern latitudes in a global coupled model. Climate Dynamics 32(6):783-798, DOI 10.1007/s00382-008-0419-1

Latif M, Martin T, Park W (2013) Southern Ocean sector centennial climate variability and recent decadal trends. Journal of Climate 26(19):7767-7782, DOI 10.1175/ JCLI-D-12-00281.1, URL https://doi.org/10.1175/JCLI-D-12-00281.1, https:// doi.org/10.1175/JCLI-D-12-00281.1

Lecomte O, Goosse H, Fichefet T, de Lavergne C, Barthélemy A, Zunz V (2017) Vertical ocean heat redistribution sustaining sea-ice concentration trends in the 
Ross Sea. Nature Communications 8:258, URL http://www.ncbi.nlm.nih.gov/ pmc/articles/PMC5557847/

Li X, Holland DM, Gerber EP, Yoo C (2014) Impacts of the north and tropical Atlantic ocean on the Antarctic Peninsula and sea ice. Nature 505(7484):538-542, DOI 10.1038/nature12945, URL https://doi.org/10.1038/nature12945

Mahlstein I, Gent PR, Solomon S (2013) Historical Antarctic mean sea ice area, sea ice trends, and winds in CMIP5 simulations. Journal of Geophysical Research: Atmospheres 118(11):5105-5110, DOI 10.1002/jgrd.50443, URL http://dx.doi.org/ $10.1002 /$ jgrd.50443

Martinson DG (1990) Evolution of the Southern Ocean winter mixed layer and sea ice: open ocean deepwater formation and ventilation. Journal of Geophysical Research: Oceans 95(C7):11,641-11,654, DOI 10.1029/JC095iC07p11641, URL http://dx.doi.org/10.1029/JC095iC07p11641

Meehl GA, Arblaster JM, Bitz CM, Chung CTY, Teng H (2016) Antarctic seaice expansion between 2000 and 2014 driven by tropical Pacific decadal climate variability. Nature Geoscience 9(8):590-595, DOI 10.1038/ngeo2751, URL https: //doi.org/10.1038/ngeo2751

Notz D, Haumann FA, Haak H, Jungclaus JH, Marotzke J (2013) Arctic sea-ice evolution as modeled by Max Planck Institute for Meteorology's Earth system model. Journal of Advances in Modeling Earth Systems 5(2):173-194, DOI 10. 1002/jame.20016

Okumura YM, Schneider D, Deser C, Wilson R (2012) Decadal-interdecadal climate variability over Antarctica and linkages to the tropics: analysis of ice core, instrumental, and tropical proxy data. Journal of Climate 25(21):7421-7441, DOI 10.1175/jcli-d-12-00050.1, URL https://doi.org/10.1175/jcli-d-12-00050.1

Park YH, Charriaud E, Fieux M (1998) Thermohaline structure of the Antarctic Surface Water/Winter Water in the Indian sector of the Southern Ocean. Journal of Marine Systems 17(1-4):5-23, DOI 10.1016/s0924-7963(98)00026-8

Parkinson CL, Cavalieri DJ (2012) Antarctic sea ice variability and trends, 19792010. The Cryosphere 6(4):871-880, DOI 10.5194/tc-6-871-2012, URL http:// www.the-cryosphere.net/6/871/2012/

Pauling AG, Bitz CM, Smith IJ, Langhorne PJ (2016) The response of the Southern Ocean and Antarctic sea ice to freshwater from ice shelves in an earth system model. Journal of Climate 29(5):1655-1672, DOI 10.1175/jcli-d-15-0501.1, URL https://doi.org/10.1175/jcli-d-15-0501.1

Pellichero V, Sallée JB, Schmidtko S, Roquet F, Charrassin JB (2017) The ocean mixed layer under Southern Ocean sea-ice: seasonal cycle and forcing. Journal of Geophysical Research: Oceans 122(2):1608-1633, DOI 10.1002/2016jc011970

Pohlmann H, Botzet M, Latif M, Roesch A, Wild M, Tschuck P (2004) Estimating the decadal predictability of a coupled AOGCM. Journal of Climate 17(22):44634472, DOI 10.1175/3209.1, URL http://dx.doi.org/10.1175/3209.1, http://dx.doi. org/10.1175/3209.1

Polvani LM, Smith KL (2013) Can natural variability explain observed Antarctic sea ice trends? New modeling evidence from CMIP5. Geophysical Research Letters 40(12):3195-3199, DOI 10.1002/grl.50578, URL http://dx.doi.org/10.1002/ grl.50578

Purich A, Cai W, England MH, Cowan T (2016) Evidence for link between modelled trends in Antarctic sea ice and underestimated westerly wind changes. Nature Communications 7:10,409 EP -, URL http://dx.doi.org/10.1038/ncomms10409, 
article

${ }_{953}$ Raphael MN, Marshall GJ, Turner J, Fogt RL, Schneider D, Dixon DA, Hosking JS, Jones JM, Hobbs WR (2016) The Amundsen Sea Low: variability, change, and impact on Antarctic climate. Bulletin of the American Meteorological Society 97(1):111-121, DOI 10.1175/BAMS-D-14-00018.1, URL https://doi.org/10.1175/ BAMS-D-14-00018.1, https://doi.org/10.1175/BAMS-D-14-00018.1

Sallée JB, Wienders N, Speer K, Morrow R (2006) Formation of subantarctic mode water in the southeastern Indian Ocean. Ocean Dynamics 56(5-6):525-542, DOI 10.1007/s10236-005-0054-x

Shaffrey LC, Stevens I, Norton WA, Roberts MJ, Vidale PL, Harle JD, Jrrar A, Stevens DP, Woodage MJ, Demory ME, Donners J, Clark DB, Clayton A, Cole JW, Wilson SS, Connolley WM, Davies TM, Iwi AM, Johns TC, King JC, New AL, Slingo JM, Slingo A, Steenman-Clark L, Martin GM (2009) U.K. HiGEM: The new U.K. high-resolution global environment model-model description and basic evaluation. Journal of Climate 22(8):1861-1896, DOI 10.1175/2008jcli2508.1

Sidorenko D, Rackow T, Jung T, Semmler T, Barbi D, Danilov S, Dethloff K, Dorn W, Fieg K, Goessling HF, Handorf D, Harig S, Hiller W, Juricke S, Losch M, Schröter J, Sein DV, Wang Q (2014) Towards multi-resolution global climate modeling with ECHAM6-FESOM. part i: model formulation and mean climate. Climate Dynamics 44(3-4):757-780, DOI 10.1007/s00382-014-2290-6

Sigmond M, Fyfe JC (2014) The Antarctic sea ice response to the ozone hole in climate models. Journal of Climate 27(3):1336-1342, DOI 10.1175/JCLID-13-00590.1, URL https://doi.org/10.1175/JCLI-D-13-00590.1, https://doi.org/ 10.1175/JCLI-D-13-00590.1

Simpkins GR, McGregor S, Taschetto AS, Ciasto LM, England MH (2014) Tropical connections to climatic change in the Extratropical Southern Hemisphere: the role of Atlantic SST trends. Journal of Climate 27(13):4923-4936, DOI 10.1175/jclid-13-00615.1, URL https://doi.org/10.1175/jcli-d-13-00615.1

Stammerjohn SE, Martinson DG, Smith RC, Yuan X, Rind D (2008) Trends in Antarctic annual sea ice retreat and advance and their relation to El Niño-Southern Oscillation and Southern Annular Mode variability. Journal of Geophysical Research: Oceans 113(C3):n/a-n/a, DOI 10.1029/2007JC004269, URL http://dx.doi.org/10.1029/2007JC004269, c03S90

Stuecker MF, Bitz CM, Armour KC (2017) Conditions leading to the unprecedented low Antarctic sea ice extent during the 2016 austral spring season. Geophysical Research Letters 44(17):9008-9019, DOI 10.1002/2017gl074691

Swart NC, Fyfe JC (2013) The influence of recent Antarctic ice sheet retreat on simulated sea ice area trends. Geophysical Research Letters 40(16):4328-4332, DOI 10.1002/grl.50820, URL https://doi.org/10.1002/grl.50820

Thompson DWJ, Solomon S, Kushner PJ, England MH, Grise KM, Karoly DJ (2011) Signatures of the Antarctic ozone hole in Southern Hemisphere surface climate change. Nature Geosci 4(11):741-749, DOI 10.1038/ngeo1296, URL http://dx. doi.org/10.1038/ngeo1296

Tietsche S, Day JJ, Guemas V, Hurlin WJ, Keeley SPE, Matei D, Msadek R, Collins M, Hawkins E (2014) Seasonal to interannual Arctic sea ice predictability in current global climate models. Geophysical Research Letters 41(3):1035-1043, DOI 10.1002/2013GL058755, URL http://dx.doi.org/10.1002/2013GL058755

Timlin MS, Alexander MA, Deser C (2002) On the reemergence of North Atlantic SST anomalies. Journal of Climate 15(18):2707-2712, DOI 10.1175/1520- 
0442(2002)015<2707:OTRONA > 2.0.CO;2, URL https://doi.org/10.1175/15200442(2002)015<2707:OTRONA > 2.0.CO;2

Timmermann R, Danilov S, Schröter J, Böning C, Sidorenko D, Rollenhagen K (2009) Ocean circulation and sea ice distribution in a finite element global sea ice-ocean model. Ocean Modelling 27(3-4):114-129, DOI 10.1016/j.ocemod.2008. 10.009

Turner J, Bracegirdle TJ, Phillips T, Marshall GJ, Hosking JS (2013a) An initial assessment of Antarctic sea ice extent in the CMIP5 models. Journal of Climate 26(5):1473-1484, DOI 10.1175/JCLI-D-12-00068.1, URL https://doi.org/ 10.1175/JCLI-D-12-00068.1, https://doi.org/10.1175/JCLI-D-12-00068.1

Turner J, Phillips T, Hosking JS, Marshall GJ, Orr A (2013b) The Amundsen Sea low. International Journal of Climatology 33(7):1818-1829, DOI 10.1002/joc.3558, URL https://doi.org/10.1002/joc.3558

Turner J, Phillips T, Marshall GJ, Hosking JS, Pope JO, Bracegirdle TJ, Deb P (2017) Unprecedented springtime retreat of Antarctic sea ice in 2016. Geophysical Research Letters 44(13):6868-6875, DOI 10.1002/2017g1073656

Watanabe M, Suzuki T, O'ishi R, Komuro Y, Watanabe S, Emori S, Takemura T, Chikira M, Ogura T, Sekiguchi M, Takata K, Yamazaki D, Yokohata T, Nozawa T, Hasumi H, Tatebe H, Kimoto M (2010) Improved climate simulation by MIROC5: mean states, variability, and climate sensitivity. Journal of Climate 23(23):6312-6335, DOI 10.1175/2010JCLI3679.1, URL http://dx.doi.org/ 10.1175/2010JCLI3679.1, http://dx.doi.org/10.1175/2010JCLI3679.1

Wong APS, Riser SC (2011) Profiling float observations of the upper ocean under sea ice off the Wilkes Land coast of Antarctica. Journal of Physical Oceanography 41(6):1102-1115, DOI 10.1175/2011jpo4516.1

Yang CY, Liu J, Hu Y, Horton RM, Chen L, Cheng X (2016) Assessment of Arctic and Antarctic sea ice predictability in CMIP5 decadal hindcasts. The Cryosphere 10(5):2429-2452, DOI 10.5194/tc-10-2429-2016, URL http://www. the-cryosphere.net/10/2429/2016/

Zunz V, Goosse H, Massonnet F (2013) How does internal variability influence the ability of CMIP5 models to reproduce the recent trend in Southern Ocean sea ice extent? The Cryosphere 7(2):451-468, DOI 10.5194/tc-7-451-2013, URL http: //www.the-cryosphere.net/7/451/2013/

Zunz V, Goosse H, Dubinkina S (2014) Impact of the initialisation on the predictability of the Southern Ocean sea ice at interannual to multi-decadal timescales. Climate Dynamics pp 1-20, DOI 10.1007/s00382-014-2344-9, URL http://dx.doi. org/10.1007/s00382-014-2344-9 